\title{
Productivity and Mobility in Academic Research: Evidence from Mathematicians
}

\author{
Pierre Dubois*, Jean-Charles Rochet ${ }^{\dagger}$ and Jean-Marc Schlenker ${ }^{\ddagger}$
}

October 2010 - revised, March 2013

\begin{abstract}
Using an exhaustive database on academic publications in mathematics all over the world, we study the patterns of productivity by mathematicians over the period 1984-2006. We uncover some surprising facts, such as the weakness of age related decline in productivity and the relative symmetry of international movements, rejecting the presumption of a massive "brain drain" towards the U.S. We also analyze the determinants of success by top U.S. departments. In conformity with recent studies in other fields, we find that selection effects are much stronger than local interaction effects: the best departments are most successful in hiring the most promising mathematicians, but not necessarily at stimulating positive externalities among them. Finally we analyze the impact of career choices by mathematicians: mobility almost always pays, but early specialization does not.
\end{abstract}

JEL Classification: D85, I23, J24, L31

Keywords: faculty productivity; organization of research; peer effects in science.

\footnotetext{
*Toulouse School of Economics, pierre.dubois@tse-fr.eu

$\dagger$ University of Zurich, Swiss Finance Institute and Toulouse School of Economics (IDEI). rochet@bf.uzh.ch

${ }^{\ddagger}$ Institut de Mathématiques de Toulouse, UMR CNRS 5219, Université Toulouse III, jmschlenker@gmail.com
} 


\section{Introduction}

In spite of a growing interest about the determinants of success in academic research, very little is known about the cross-country and intertemporal patterns of productivity by researchers and universities. Most studies focus or only one country (typically the U.S.) and very often only look at a small number of journals, a subset of universities and a limited time period. For example Laband and Tollison (2000) compare the patterns and impact of scientific collaboration in economics and biology, but they focus on the three top academic journals in each field and only look at U.S. universities. Oyer (2006) looks at the impact of initial placement on the career of $\mathrm{PhD}$ economists but he only looks at the economists who graduated in seven U.S. economics departments. Similarly, when Agrawal and Goldfarb (2008) look at the impact of Bitnet (an early version of Internet) on university research output in engineering, they only look at U.S. universities on the period 1981-1991. Even if Kim et al. (2009) consider a longer time interval (1970-1999) in their study of the impact of new information technologies, they only look at U.S. universities. As suggested by Coupé (2003), this might be due to a comprehensible "home bias" ( "U.S. economists rank U.S. institutions,...Canadian economists restrict themselves to Canadian departments,..., Asian economists focus on Asian departments" Coupé (2003) p1309) but lack of data must also play a role, and more precisely the difficulties that arise when trying to use worldwide data sets on academic research outputs.

There is an important exception to this lack of structured and easy to use data: the American Mathematical Society maintains an almost exhaustive database (Mathematical Reviews) of publications in mathematical journals all over the world. This unique database ${ }^{1}$ provides a fantastic opportunity for studying the international and inter-temporal patterns of academic research.

Mathematics is an interesting field to study when thinking of knowledge production. Indeed, this discipline is special in several ways: (i) there is relatively little equipment needed to do research, unlike biology, physics and engineering or even economics and psychology, (ii) many papers are still written by

\footnotetext{
${ }^{1}$ To our knowledge, Borjas and Doran (2012) are the only ones to use the same source of data. They study the effects of the collapse of the Soviet Union and the influx of Soviet mathematicians after 1992 on the productivity of their American counterparts.
} 
single authors, partly defying the trend documented by Wuchty et al. (2007); Jones (2010), (iii) language barriers are perhaps less important than in other fields, (iv) (relatedly) elite mathematical research departments are relatively international, (v) math is less constrained by local interests than social sciences (i.e. Americans may care most about the US economy), the humanities (i.e. the French may disproportionately care about French literature), and even engineering (i.e. Australians may disproportionately care about geological engineering), Therefore, out of all fields, the underlying structure of knowledge production in mathematics suggests that local effects should be relatively unimportant. This means that, in addition to the availability of a rich dataset, mathematics is useful to study because many of the constraints associated with knowledge production are less binding than in other fields.

The quality of the Mathematical Reviews data is apparent in several ways, two of which are of particular relevance here. The first is that it is almost exhaustive: it covers the worldwide mathematical production over the period studied here, 1984-2006. As explained below, we focus attention on a subset of mathematicians and journals, but our sample is remarkably large: we are able to study the academic output of the 32574 mathematicians who were active all over the world over the period 1984-2006. The second important way in which our data set is unique is that it is remarkably well structured and easy to use: each institution and each author can be identified without ambiguity, as well as the main and secondary fields of the articles. This allows to identify precisely all the career decisions made by mathematicians: choice of fields and co-authors, and more importantly mobility decisions. All movements of a researcher from one university (and one country) to another can be perfectly tracked down, at least for mathematicians who remain active (i.e. continue to publish), the focus of our interest in this article. We are thus able to identify international and inter-departments movements of mathematicians at the aggregate level and simultaneously to assess the impact of these movements on the individual productivity of researchers. Given that at least some proportion of this mobility is due to exogenous reasons (other than offers made to the best mathematicians by the most prestigious institutions), we can estimate the impact of mobility on the future productivity of researchers. For the same reason, 
we can assess the impact of career decisions (specialize or not, collaborate or not,...) on the success of a mathematician. Even though mathematics clearly has its own specificities (we will come back to these specificities later), we are convinced that our study can also be useful for understanding the determinants of academic success in other fields.

The first part of the article provides detailed descriptive statistics on academic production by mathematicians and uncovers some surprising facts. For example, contrary to a widely held belief (among both scientists and lay people) the rate and quality of mathematical production does not decline rapidly with age. For mathematicians who remain scientifically active, productivity typically increases over the first 10 years, then remains almost constant until the end of their career. However there is a substantial attrition rate (i.e. mathematicians who stop publishing) at all ages. ${ }^{2}$ Another surprising fact is how fast the shares of mathematical production by different countries have changed in the recent years. The U.S. are still by far the largest country in terms of mathematical production, but their share has declined from 50\% in 1984 to $34 \%$ in 2006. While this phenomenon has been documented elsewhere(see e.g. Hill et al. (2007)) the magnitude of the U.S. decline in mathematics is striking. It contrasts with other areas of science and engineering, where the share of the U.S. in world scientific production was found to decrease much more slowly. ${ }^{3}$ Similarly, the share of China in mathematics is rapidly increasing but it is still surprisingly low as measured by our indicators, which put a strong weight on the most selective journals (only $3.8 \%$ in 2006). Another surprising fact is that international mobility after the $\mathrm{PhD}$ is rather weak and it is much more symmetric than could be expected, both in terms of numbers of mathematicians and in terms of "quality", as measured by the output of the mathematicians who change countries.

In the second part of the article we perform a detailed statistical analysis of the factors that can influence the scientific production of academic mathematicians. This allows to analyze the determinants of individual productivity all

\footnotetext{
${ }^{2}$ For comparable studies in other fields see Levin and Stephan (1991) and Stephan (2008).

${ }^{3}$ This is consistent with Annex Table 3 in Hill et al. (2007), where mathematics appears as an area where the U.S. share of world output has decreased the most from 1988 to 2003. Our data show a continuation of this trend up to 2006.
} 
along a mathematician's career, taking into account the (unobserved) intrinsic "talent" of each mathematician through fixed effects. Among the important factors is of course location: the best mathematicians are (by definition) found in the best departments, but causality is not clear. Using the mobility of a sizable subset of these mathematicians (as in Kim et al. (2009)) we can separate the selection effects (hiring the most promising mathematicians) from interaction effects (stimulating positive spill-overs through exchange of expertise and feedback among colleagues).

In conformity with other recent studies ( e.g. Waldinger (2012)), we find that university fixed effects (once researchers intrinsic quality is accounted for) are in general small, and are not strongly correlated with the quality of the department. A few departments have a strong positive impact on their members' productivity but in prominent examples this is largely associated with prestigious locally managed journals, which seem to publish relatively many articles from "locals".

We also analyze the impact of other characteristics of departments on the outputs of their members and find several interesting facts. First, we find that size does matter: large departments are good for individual productivity. However this effect is largely due to good hirings and becomes negligible when authors fixed effects are incorporated. Then, it appears that having a specialized department has a negative impact on productivity when no fixed effect is used, but this impact becomes positive with fixed effects. This tends to indicate that a narrower scope lowers the quality of hiring, but that researchers fare better in a department with colleagues close to their mathematical interests. Looking at US universities, we find several interesting results. First, money does not seem to matter much: even if the endowment per student has a strong positive impact when authors fixed effects are not used, it has a negative impact (although not very significant) when these fixed effects are incorporated. This negative effect becomes more significant when taking into account the fact that the university is public or private. Second, the fact that a US university is private has a small positive effect compared to public ones. There is also a sizable positive effect of location on the East Coast relative to the Mid-West, the West Coast standing in between the two.

Finally we analyze the impact of career decisions of individual researchers. 
We obtain some additional interesting results on collaborations, mobility and specialization. Collaborations have a globally negative effect: the total output of mathematicians who have more collaborating authors tends to be lower than the output of those who work separately. However collaborating with authors of a different specialty is positive: interdisciplinary work (within mathematics) spurs productivity. Concerning mobility, we find that each move increases future production. Regarding specialization, we provide evidence that a high level of specialization is not a good strategy: it is correlated to a lower future output, in particular for young researchers. This suggests that researchers should be encouraged, especially at a younger age, to keep a broad range of interests.

The remainder of the paper is organized as follows. Section 2 presents the data. Section 3 gives some descriptive statistics on these data. Section 4 analyzes the determinants of scientific ouput of mathematicians. Section 5 concludes.

\section{Data description}

\subsection{The Mathematical Reviews database}

The data come from the Mathematical Reviews database, which is maintained by the American Mathematical Society. ${ }^{4}$ This database provides an almost exhaustive source of information on publications in mathematics, covering almost all journals publishing mathematics-related articles and many books and conference proceedings. It is remarkably well structured and has three features that make it particularly well suited to a statistical use. First, it provides a personal identification of each individual author, so that there is no ambiguity even when two authors have the same name and initials. Second, each institution is identified by a unique institution code. Last, each article is assigned one or more codes describing its principal and secondary fields within mathematics using the "mathematical sciences classification (M.S.C.)". This gives a precise description of an article's area within mathematics.

\footnotetext{
${ }^{4}$ We are grateful to Mathematical Reviews for allowing us to use their database in a nonstandard fashion.
} 
A small portion of the Mathematical Reviews database was used: since our focus was on "active" mathematicians, we selected the 98 journals with the highest impact factor (according to the 2006 Journal Citation Report in pure and applied mathematics), and compiled a list of all 129242 articles published in those journals between 1984 and 2006. Those 98 journals are the most visible in the fields of pure and applied mathematics, so that our data paints a reasonably accurate picture of the best part of mathematical research. We chose 1984 as the starting date because Mathematical Review only records the affiliation of authors from this date.

We then compiled a list of all 32574 mathematicians who published at least two articles in those 98 journals over this period. For these mathematicians, we compiled a list of the dates of their first and last publications in the whole database (not just the 98 journals in our restricted list). We focused mainly, but not exclusively, on this smaller group of "active" mathematicians. The others, those with only one article in our list of 98 journals, can be of different types: mathematicians publishing few papers, mathematics $\mathrm{PhD}$ who have left the field, or academics of another field who have collaborated to a project published in a mathematics journal, etc.

\subsection{Impact}

For a correct assessment of the activity of the mathematicians in our list, we did not use the most standard impact factor data, which covers all scientific areas but is of limited relevance for mathematics (Adler et al. (2009)). Instead, the impact of each journal in the mathematical community was evaluated by its 2007 Mathematical Citation Quotient (MCQ), which is a kind of impact factor computed over five years. It is defined as the mean number of citations, within 5 years of publication, in a relevant part of the mathematical literature. This $M C Q$ is highly correlated with the impact factor as computed by Thomson Reuters, but it is less volatile and appears to be much more relevant for mathematical journals. Moreover the impact factor tends to generate biases between subfields of mathematics.

However the $M C Q$ is only an indication of the "quality" of a journal as 
evaluated by most mathematicians, rather than an absolute measure. In order to have a reasonable assessment of the importance of an article, we decided to assign to each article a weight equal to the product of its number of pages by the square of the $M C Q$ of the journal where it was published. In this way, longer articles have a (linearly) higher weight. This is chosen in view of the general practice in mathematics: selective journals tend to be more demanding towards long papers, and to accept more easily short notes. The square is justified by the desire to emphasize good quality journals. Doing so, the weight of a page varies within our limited list of journals in a ratio of approximately 1 to 100. Putting a much stronger weight on a small number of highly selective journals, as we do by taking the square of the MCQ, also reflects the confidence that most mathematicians still have in the quality of peer review in the most selective journals. This might not be the case in other areas, see for instance Ellison (2011) for questions on the value attached to publications in top journals in economics, or Ellison (2012) for an analysis of the (quite different) situation in computer science.

Our choice of weights puts a strong emphasis on a small number of very selective journals, as can be seen from the list of journals in the appendix. This selectivity is in conformity with the most widely shared quality assessments within the community of mathematicians. However, we have checked that choosing a different weight on articles does not change significantly the results of our study. There are probably some biases in the way different fields are treated (for instance journals in applied mathematics tend to have a lower $M C Q$ than those in pure mathematics), but this is controlled for in our regressions by using the field of research as a control variable.

A key point, however, is that the main results obtained here do not depend on the precise indicator used. We give in Appendix B some results duplicating those presented in the paper with different quality measures, replacing in particular the $M C Q$ by the more familiar Impact Factor (IF), which is more commonly used in natural sciences but seems less well adapted to mathematics. In this appendix, the weight of each paper is the product of its length (number of pages) by the mere $I F$ of the journal where it is published (as opposed to its square that we use in our other regressions). As the reader can check, our main results 
do no change much if we adopt these quite different measures of output. Smaller changes - like suppressing the square on the $M C Q$ - have an even smaller impact on the results.

To achieve a better understanding of these differences between fields within mathematics, we used the Mathematical Subject Classification (M.S.C.) codes assigned to each article by Mathematical Reviews. Since this classification is quite detailed, we grouped different M.S.C. codes so as to obtain only 10 different areas. There are sizable differences between the characteristics of articles in different fields of mathematics, as seen in Table 12 in the appendix. We also indicate in this table the number of authors and of articles for each field, so as to give an idea of their relative numerical importance. It shows simply that Probability and Statistics is the largest field while Analysis is second followed by Partial Differential Equations, Differential Geometry, Numeric Methods and Physics. Topology and Algebra come after and the smallest field is Dynamical Systems.

Finally, we compute yearly author impacts by summing the impact measures divided by the number of authors of all the articles they have published within a year.

Any method for attributing "weights" to scientific articles and thus to researchers' outputs has necessarily some degree of arbitrariness. There is a growing literature trying to determine the best way to measure scientific output. For instance, Hirsch (2005) proposes to measure the productivity of authors by the so-called h-index. This index is criticized by Ellison (2010). Palacios-Huerta and Volij (2004) propose a new index based on citations but different from the traditional impact factor. Combes and Linnemer (2003) propose a ranking of journals in economics based on peer assessment of journal quality in addition to citations instead of a purely objective measure using citations counts. Consistently with Korevaar (1996), we believe that our way of weighting articles gives a result that is not too far from the heuristic assessment of many mathematicians, but we have not, at this point, tried to make this precise. It is probably not well adapted to other scientific areas. 


\section{Descriptive statistics}

This section contains general data on the spread of mathematical research (as measured by our indicators) in the world, on collaborations between regions and on mathematicians moving from one country to another. We also consider evolutions over time. Location of mathematicians can be identified thanks to their university affiliation as recorded in publications. The list of coauthors and their affiliations as well as the evolution over time of affiliations for a given author allowed us to identify international collaborations as well as movements of mathematicians.

\subsection{Countries and regions}

\subsubsection{The weight of different regions over time}

In the following results, we present statistics for the ten countries having the biggest mathematical production, which are, by alphabetical order, Canada (CA), France (FR), Germany (GER), Israel (IL), Italy (IT), Japan (JAP), the People's Republic of China (PRC), Spain (SP), Britain (UK), and the United States (US). Russia (including the former U.S.S.R. before 1989) does not appear among them because most Russian mathematicians were publishing for a long time in domestic journals in Russian that had consequently low impact factors because rarely read by the international community.

\begin{tabular}{lllllllllllllll}
\hline & \multicolumn{11}{c}{ Country } \\
Years & CA & FR & GER & IL & IT & JAP & PRC & SP & UK & US & OTH \\
\hline $1984-1986$ & 2.1 & 10.4 & 6.5 & 1.2 & 1.7 & 3.4 & 0.2 & 0.8 & 4.0 & 50.9 & 11.9 \\
$1987-1990$ & 2.8 & 10.6 & 5.9 & 1.4 & 2.3 & 3.2 & 0.7 & 1.0 & 4.0 & 50.6 & 13.3 \\
$1991-1994$ & 3.6 & 11.0 & 6.0 & 2.1 & 2.6 & 3.7 & 0.9 & 1.2 & 3.7 & 49.8 & 11.5 \\
$1995-1998$ & 3.7 & 11.3 & 7.2 & 2.3 & 3.1 & 3.6 & 1.3 & 1.6 & 4.4 & 44.2 & 12.9 \\
$1999-2002$ & 2.6 & 12.5 & 6.8 & 3.0 & 3.2 & 3.6 & 2.6 & 2.1 & 4.8 & 38.9 & 13.0 \\
$2003-2006$ & 3.2 & 12.6 & 6.3 & 1.8 & 3.9 & 3.9 & 3.1 & 2.5 & 4.6 & 36.3 & 13.3 \\
\hline
\end{tabular}

Table 1: Share of countries in the world production, over time (in percentage points)

Table 1 shows the proportion of world output coming from different countries, over time. Two striking features are the decrease in the share of the U.S. 
and the increase in the share of China, which however remains quite low.

\subsubsection{Collaborations}

As shown by table 13 in the Appendix, the evolution over time of the proportion of international collaborations is particularly impressive for Russia. Before the fall of the Soviet Union in 1989, it was difficult for Russian mathematicians to collaborate with foreign colleagues. After 1989, a large proportion of the most active Russian mathematicians moved to other countries, which can account for the high proportion of collaborations between mathematicians located in Russia and those in other countries.

Note that the proportion of collaborations in the U.S. was initially quite low $(25 \%)$ but is has increased markedly over the period.

\subsubsection{International mobility}

Table 14 in the Appendix shows the percentage of total number of years spent in different countries by active mathematicians with a known first location in a given country. The total in each row is the total number of years for which an affiliation is known for any of the mathematicians in our database with first affiliation in the corresponding country, and the total in each column is the total number of years spent in each country by mathematicians with a known affiliation.

Table 14 contains a precise indication of the gain/loss of each country from the "brain-drain", seen by comparing the total on a column (number of years spent in a country by active mathematicians ) to the total on the corresponding row (number of years spent by active mathematicians with first career affiliation in the country). For instance the U.S. benefit from the flow (25921 years spent by active mathematicians in the US, vs. 22882 years spent anywhere by mathematicians with location in the U.S.) while Russia loses (210 vs. 330 years).

The variable "first location" is defined as follows. We know the affiliation of mathematicians for each year in which they have published a paper in one of the journals in our list. However we also have, for each mathematician in our list, 
the date of their first publication (in any journal, not necessarily those in our list). We define the "first location" with the first affiliation that we know of, if it is within 3 years of the first publication. As a consequence we know the first location of only 10803 of the 32437 "active" mathematicians in our database. In particular we do not know the "first location" of any mathematician with first publication before 1981, since our list of articles starts in 1984 .

In general, this "first location" indicates the country where mathematicians have completed their $\mathrm{PhD}$, or the country of their first or second year of postdoc. We only consider here mathematicians for whom we know the affiliation of first publication.

A striking feature of Table 14 is the relatively small number of mathematicians who have changed countries: the vast majority remains in the country of their first location. The only exception is the high number of moves between Canada and the U.S., in both directions. However, as mentioned above, the sums of the rows and columns corresponding to each country indicate the gain/loss from the flows, which are close to $10 \%$ for countries like the U.K. (loss) or the U.S. (gain).

Table 15 in the Appendix gives a hint on the attractivity of different regions. It shows the mean impact of mathematicians working in a given region, depending on the region where they had their first publication, which is typically the region where they did their PhDs. Therefore these results must be interpreted with caution, given that apparent "migrations" may correspond to an authentic "brain drain" but also to a mere return to the country of birth. A second reason for caution is that the numbers involved (e.g., migrations from Germany to Japan) maybe quite small.

\begin{tabular}{lrrrrrrrrrrr}
\hline & \multicolumn{11}{c}{ Country } \\
Origin & CA & FR & GER & IL & \multicolumn{1}{c}{ IT } & PRC & RUS & SP & UK & US Total \\
\hline Locals & 4.9 & 12.4 & 8.2 & 8.9 & 5.6 & 4.1 & 6.3 & 4.7 & 6.6 & 8.9 & 8.0 \\
Migrants & 11.9 & 17.3 & 13.1 & 10.4 & 11.8 & 8.9 & 8.5 & 11.3 & 12.2 & 13.3 & 10.4 \\
Average & 7.7 & 13.1 & 8.9 & 9.3 & 6.6 & 5.1 & 6.4 & 5.3 & 8.1 & 9.4 & 8.5 \\
\hline
\end{tabular}

Table 2: Mean impact of mathematicians with first location in/out the country of their current location

Table 2 has an interesting implication: in almost all regions, the mathemati- 
cians having their first location outside their current region ("migrants") have a better mean impact than those with a local first location ("locals"). Here again the explanation can vary between countries; in some cases it can be that the most active scientists tend do be those who went abroad to do their $\mathrm{PhD}$ before coming back, while some other countries actually drain the most active scientists. ${ }^{5}$

\begin{tabular}{lr}
\hline Country & Proportion \\
\hline Canada & 0.39 \\
France & 0.15 \\
Germany & 0.15 \\
Israel & 0.29 \\
Italy & 0.16 \\
Japan & 0.05 \\
China & 0.20 \\
Spain & 0.10 \\
United Kingdom & 0.26 \\
United States & 0.12 \\
\hline
\end{tabular}

Table 3: Proportion of mathematicians residing in one country and "coming from" (having had their first publication in) another country.

The proportion of "migrants", i.e. mathematicians having their first location in a different region than their current location is shown in Table 3. These proportions are an indication of how attractive a country is for foreign mathematicians, and of how open its institutions are to mathematicians with a foreign $\mathrm{PhD}$. Canada strikes out as particularly open. The relatively high figure for China is certainly a measure of the number of mathematicians returning to China after a $\mathrm{PhD}$, and therefore a first publication, in another country. The small number for the US is also due to the fact that a lot of migration towards the US is done before and not after the $\mathrm{PhD}$.

We have not included Russia in this table because, as mentioned above, its researchers could not publish before 1989 in the journals of our list. As a consequence we cannot reliably identify their first affiliation, which skews the results for this country.

\footnotetext{
${ }^{5}$ The data in Table 15 and in Table 2 is more or less significant depending on the countries, as indicated in the numbers of mathematicians concerned, as seen in Table 14 in Appendix and in Table 3.
} 
Up to this point we have only considered the relationship between the first location of mathematicians and their locations when they publish new articles. We now concentrate on "permanent" moves between regions, defined as follows: mathematicians who have spent at least 3 years in a given region, then moved to another region and spent at least 3 years there. This excludes short moves for short-term post-doctoral positions or sabbaticals, but also changes of country immediately following the first publication. Tables 16 and 17 in the Appendix show these modified "migration" data and illustrate three striking facts. First, the number of such "permanent" moves between countries is small (see Table 16). Second, the numbers of "permanent" moves between most couples of countries are remarkably symmetric. Third, the "quality" of those moves, as measured by the mean impact of the mathematicians moving between countries, is also remarkably symmetric as shown in Table 17 in the Appendix. Our data tends to indicate that the "brain-drain" phenomenon happens mostly for young researchers who move before or after their $\mathrm{PhD}$ or after a few years of post-doc. Incidentally, this finding suggests that investing a lot in $\mathrm{PhD}$ programs attended in large part by foreigners, like the US does, might turn out to be a very good idea, given the fact that a large proportion of these foreign students does not return in their country of origin.

\subsection{Universities}

\subsubsection{General description}

Table 4 shows the share of world output (measured by our indicator) for the top 20 departments (also ranked by this indicator), and its variation over time. It shows notable changes in the ranking of departments, both upwards and downwards. Another feature is that the production of mathematical literature, even when measured by our quite elitist indicator, is not very concentrated. Indeed, the department ranked first produces only $1.8 \%$ of the world total output (weighted by impact) over the whole period. Moreover this concentration appears to decrease over time, since the share of the most active department was $2.25 \%$ in $1989-1994$, but only $1.7 \%$ in $2001-2006$.

Table 18 in the Appendix shows the size (yearly average number of active 


\begin{tabular}{|c|c|c|c|c|c|c|}
\hline University & Rank Share & of impact & 1984-88 & 1989-94 & $1995-2000$ & $2001-06$ \\
\hline Princeton & 1 & 1.80 & 2.15 & 1.96 & 1.61 & 1.70 \\
\hline Paris 11 (FR) & 2 & 1.73 & 1.73 & 2.25 & 1.56 & 1.50 \\
\hline MIT & 3 & 1.58 & 1.94 & 1.94 & 1.44 & 1.30 \\
\hline NYU & 4 & 1.44 & 1.63 & 2.05 & 1.49 & 0.89 \\
\hline Berkeley & 5 & 1.39 & 1.80 & 1.44 & 1.34 & 1.21 \\
\hline Harvard & 6 & 1.27 & 1.94 & 1.18 & 1.38 & 0.94 \\
\hline Paris 6 (FR) & 7 & 1.27 & 1.27 & 1.26 & 1.42 & 1.14 \\
\hline Chicago & 8 & 1.09 & 1.23 & 1.06 & 1.07 & 1.08 \\
\hline UCLA & 9 & 0.97 & 1.26 & 1.30 & 0.75 & 0.79 \\
\hline Stanford & 10 & 0.93 & 0.99 & 1.16 & 0.83 & 0.84 \\
\hline Michigan & 11 & 0.93 & 0.64 & 0.90 & 1.18 & 0.85 \\
\hline Rutgers & 12 & 0.92 & 1.09 & 1.08 & 1.04 & 0.63 \\
\hline Purdue & 13 & 0.91 & 1.53 & 1.08 & 0.75 & 0.64 \\
\hline Minnesota & 14 & 0.86 & 0.87 & 1.24 & 0.68 & 0.75 \\
\hline Maryland & 15 & 0.85 & 1.26 & 1.06 & 0.84 & 0.53 \\
\hline IAS Princeton & 16 & 0.79 & 0.89 & 0.82 & 0.89 & 0.63 \\
\hline Toronto & 17 & 0.77 & 0.46 & 0.88 & 0.82 & 0.79 \\
\hline Ohio State & 18 & 0.75 & 0.75 & 0.80 & 0.82 & 0.63 \\
\hline Columbia & 19 & 0.72 & 1.15 & 0.83 & 0.62 & 0.54 \\
\hline Wisconsin & 20 & 0.71 & 0.91 & 0.68 & 0.56 & 0.77 \\
\hline
\end{tabular}

Table 4: Percentage shares of the world output over time, top 20 departments

mathematicians) and the share, in total output, of the top author, and then the top 5 and top 10 authors (again weighted by impact). The share of the most productive author typically varies between $5 \%$ and $15 \%$, while the share of the top 10 authors varies between $23 \%$ and $70 \%$, depending on the size of the department.

Table 5 shows the top 20 departments by total output, ranked now in terms of the average output of their researchers (among departments with a total output of at least 5000 weighted pages over the period, so as to eliminate very small departments). There is a large difference between the two rankings, since small departments with highly productive researchers (like the Institute for Advanced Studies) have excellent rankings in terms of average output but not in terms of total output. The top department by mean output is the I.H.E.S. (Institut des Hautes Etudes Scientifiques, Paris), but it does not appear in the table since it is not part of the top 20 departments by total output. 


\begin{tabular}{|c|c|c|c|c|}
\hline Rank & University & Total Impact & Rank by mean & Mean Impact \\
\hline 1 & Princeton & 42522 & 3 & 25.7 \\
\hline 2 & Paris 11 (FR) & 40800 & 6 & 20.1 \\
\hline 3 & MIT & 37408 & 13 & 16.1 \\
\hline 4 & NYU & 34136 & 7 & 19.3 \\
\hline 5 & Berkeley & 32770 & 27 & 12.0 \\
\hline 6 & Harvard & 30002 & 4 & 25.0 \\
\hline 7 & Paris $6(\mathrm{FR})$ & 29931 & 36 & 11.4 \\
\hline 8 & Chicago & 25875 & 8 & 17.8 \\
\hline 9 & UCLA & 22835 & 23 & 13.4 \\
\hline 10 & Stanford & 22074 & 31 & 11.7 \\
\hline 11 & Michigan & 21931 & 51 & 10.1 \\
\hline 12 & Rutgers & 21724 & 40 & 11.1 \\
\hline 13 & Purdue & 21477 & 29 & 11.9 \\
\hline 14 & Minnesota & 20387 & 57 & 9.4 \\
\hline 15 & Maryland & 20122 & 39 & 11.2 \\
\hline 16 & IAS Princeton & 18592 & 2 & 33.2 \\
\hline 17 & Toronto & 18157 & 33 & 11.6 \\
\hline 18 & Ohio State & 17625 & 42 & 10.8 \\
\hline 19 & Columbia & 16987 & 14 & 15.8 \\
\hline 20 & Wisconsin & 16755 & 62 & 8.9 \\
\hline
\end{tabular}

Table 5: Rank for total output vs rank for mean output

\subsubsection{Where are the most active mathematicians?}

Table 6 shows the ranking of the 30 top departments by total output, along with their size (mean number of active authors) and average share (\%) over the period of the top 100 authors by total output, and the share of those among the top 500 by total output. The table shows relatively little concentration of the mathematicians with the highest output in the top departments, indicating again the relatively high number of departments taking part in top-level research. The last column shows the share of young mathematicians (those at most 4 years after their first publication), it gives an indication of the concentration of future active mathematicians (those which end up in our list) in the departments, and therefore of the importance of departments as a breeding ground for future mathematicians. 


\begin{tabular}{|c|c|c|c|c|c|}
\hline University & Rank & Size & Share top 100 & Share top 500 & Share young \\
\hline Princeton & 1 & 96.9 & 8.73 & 3.82 & 0.76 \\
\hline Paris $11(\mathrm{FR})$ & & 105.5 & 4.23 & 3.21 & 0.64 \\
\hline MIT & & 123.2 & 3.04 & 2.59 & 0.96 \\
\hline NYU & & 102.5 & 4.83 & 2.34 & 0.61 \\
\hline Berkeley & 5 & 146 & 2.11 & 2.56 & 0.9 \\
\hline Harvard & & 64.9 & 5.04 & 2.85 & 0.55 \\
\hline Paris 6 (FR) & & 143.1 & 2.01 & 1.51 & 0.77 \\
\hline Chicago & 8 & 81.1 & 2.22 & 2.43 & 0.62 \\
\hline UCLA & 9 & 93.8 & 3.36 & 1.24 & 0.47 \\
\hline Stanford & & 106.7 & 2.11 & 1.9 & 0.7 \\
\hline Michigan & & 111.8 & 0.11 & 1.74 & 0.69 \\
\hline Rutgers & & 104.2 & 2.01 & 1.74 & 0.39 \\
\hline Purdue & & 95.5 & 2.44 & 1.59 & 0.45 \\
\hline Minnesota & & 116.5 & 0.22 & 0.92 & 0.73 \\
\hline Maryland & 15 & 95.6 & 2.49 & 1.65 & 0.37 \\
\hline IAS Princeton & 16 & 33.2 & 2.39 & 1.28 & 0.22 \\
\hline Toronto & 17 & 78.7 & 1.19 & 1.4 & 0.44 \\
\hline Ohio State & 18 & 86 & 1.36 & 0.86 & 0.43 \\
\hline Columbia & 19 & 57.2 & 2.49 & 1.42 & 0.38 \\
\hline Wisconsin & 20 & 101.3 & 0.11 & 1.17 & 0.5 \\
\hline
\end{tabular}

Table 6: Share of total number of years spent by very active (resp. active, resp. young) mathematicians (mean over period of study)

\section{Analysis of the scientific output of mathemati- cians}

We now undertake a more elaborate analysis of the determinants of scientific "productivity" for mathematicians.

For such an analysis, we postulate that the output measure of mathematician $i$ during period $t$, denoted $y_{i t}$, follows a linear model :

$$
y_{i t}=\alpha_{i}+\theta_{u(i, t)}+\gamma_{f(i, t)}+\delta_{t}+\beta X_{i t}+\varepsilon_{i t}
$$

where $u(i, t)$ is the university of author $i$ at year $t, f(i, t)$ is the field of research of author $i$ at year $t, \delta_{t}$ is a period effect, $X_{i t}$ are time varying characteristics of author $i$ (for example, age, age squared, age cubed and number of coauthors) and $\alpha_{i}$ is a fixed effect for author $i$ capturing the effect of all unobserved characteristics of the author (fixed over time) that affect his or her productivity. 
Assuming that $\varepsilon_{i t}$ is mean independent of $\alpha_{i}, \theta_{u(i, t)}, \gamma_{f(i, t)}, \delta_{t}, X_{i t}$, we can identify all parameters using Ordinary Least Squares (OLS). For inference, we use clustered standard errors at the level of each author.

A causality interpretation can be done,provided all right hand side variables in this equation are exogenous. This means that the unobserved heterogeneity of authors that is correlated with productivity and with some of the right hand side variables (like the university or the number of coauthors) is fixed over time. This assumption would be invalid if, for example, universities would hire mathematicians based on temporary and unobserved shocks of productivity, therefore correlated with $\varepsilon_{i t}$.

Our first strategy is based on the use of author fixed effects to account for the endogeneity of placement of mathematicians in departments. As no experimental framework is possible in this area and we cannot really justify any natural experiment that would allocate randomly researchers to academic departments, we believe that fixed effects is a good strategy in such a reduced form estimation. In order to account for the possible correlation between unobserved university quality and moving decisions, we also estimate a specification where we add university fixed effects in $\theta_{u(i, t)}$. An alternative strategy, consisting to estimate a fully structural model of hiring and moving decisions, is beyond the scope of this paper. However, moving from one department to another is a costly decision that is not likely to be subject to unexpected and temporary shocks in performance of authors such that the correlation between performance and placement of authors is more likely to be due to the long term performance level of researchers, something captured by the author fixed effect in our specification. We thus consider that this fixed effect strategy is quite powerful in controlling for the endogeneity of the department where mathematicians are enrolled. The only sort of endogeneity that our empirical strategy cannot account for is when both unobserved deviations from its mean of university quality and author productivity shocks are correlated. This simultaneity bias would prevent us to identify the causal effect of university characteristics on author performance but we don't believe that it is likely an important problem. We'll have to keep this caveat in mind when interpreting results though.

With this specification, $\theta_{u(i, t)}$ can be interpreted as the effect of the univer- 
sity or department on the output of individual $i$. This effect can be identified because mathematicians move from departments to departments and thus $u(i, t)$ is not fixed over time. Therefore $\theta_{u}$ identifies the average effect of university $u$ on mathematicians who have been affiliated to that university in year $t$ : by definition of the indicator $u(i, t)$, they are such that $u(i, t)=u$. Similarly $\gamma_{f(i, t)}$ can be identified because not all authors publish always in the same field and thus variations at the individual level of fields of publication allow the identification of "field effects" in addition to individual effects. One alternative model consists in assuming that there is no unobserved heterogeneity across authors and thus that $\alpha_{i}=\alpha$ for all $i$ or that the deviations from the mean $\alpha_{i}$ are mean independent of all other right hand side variables of the previous equation. Then, one can add non time varying variables in the $X_{i t}$ and still identify their effect.

We estimate several variants of the specification of equation (1) and first start with the analysis of the determinants of individuals performance in terms of author impact. Then, we consider in more details the effect that departments qualities on researchers, then the effect of specific characteristics of departments. Finally, we focus on results for U.S. departments and provide more detailed evidence on the life-cycle of authors performances.

\subsection{Determinants of Individuals' Impacts}

We estimate equation (1) with several individual characteristics as explanatory variables $X_{i t}$. These explanatory variables are the number of co-authors, and the current number of co-authors from different fields, some variables on authors' personal histories like the total number of past co-authors, the number of subfields (or mathematical subject classifications (M.S.C. code )) in which they have published, and the number of institutions where they have held a position. More precisely, we have defined the number of co-authors (at a given time period) as simply the number of total coauthors who co-signed a publication with the author (co-authorship with the same coauthor for several publications in a year are infrequent but counted). We also determine the main specialty of each author by the most frequent M.S.C. code among his or her publications and define field fied effects according to this specialty. This also allows us to measure 
a second indicator of collaborations, namely the number of co-authors having a different specialty. The number of past moves between two departments is the number of times that the author has changed location since his first publication (recall that changes of location are identified only when the author publishes). The number of past M.S.C. codes of each author is the number of sub-fields measured by M.S.C. codes of his articles in his past publications records and the number of past co-authors is measured simply with past articles published that are co-authored.

Column (1) of Table 7 estimates equation (1) by OLS with the author impact as dependent variable but without author or university fixed effects ${ }^{6}$. In column (2), we add author fixed effects as unobserved heterogeneity on authors research quality may be correlated with several right hand side variables and bias the coefficients estimates. Then, in column (3), we also add university fixed effects because unobserved university specific effects may affect the performance of researchers and be correlated with their co-authorship and other right hand side variables. Remark that the sample size drops when we have both author and university fixed effects, mostly because we need both authors moving universities and varying right hand side variables in order to identify those coefficients. Finally, in columns (4) and then (5) we keep the author and university fixed effects but also instrument first the number of coauthors (in column (4)) and then both the number of coauthors and the number of coauthors in different specialties (in column (5)) with the same variables lagged twice in order to avoid some simultaneity bias in the change in the number of coauthor and the change in the author impact.

A remarkable finding in Table 7 is that the current number of co-authors has a negative impact ${ }^{7}$, with or without author fixed effects, but also with university fixed effects or when we account for some possible simultaneity bias by instrumenting the number of coauthors by its lagged value. This suggests that generally speaking, collaboration does not spur productivity: the output of a group of researchers, measured in terms of weighted pages published, is

\footnotetext{
${ }^{6}$ In all tables, ${ }^{* * *}$ means that the coefficient estimate is significantly different from zero at 1 percent level, $* *$ at 5 percent and $*$ at 10 percent.

${ }^{7}$ Recall that in our individual output measure, the impact of each paper is shared between the authors.
} 
lower than it would have been if each of them had worked separately. Moreover, the comparison of coefficients estimates in column (3) and (4) shows that instrumenting the number of coauthors reduces the absolute value of the negative effect on author impact, showing that time varying unobserved factors increasing author impact are negatively correlated with the current number of coauthors.

\begin{tabular}{lccccc}
\hline Dependent Variable: & $(1)$ & $(2)$ & $(3)$ & $(4)$ & $(5)$ \\
Author Impact & OLS & OLS & OLS & 2SLS & 2SLS \\
\hline Explanatory Variables: & \multicolumn{1}{c}{. } & & & & \\
Nb. of coauthors & $-1.598^{* * *}$ & $-1.224^{* * *}$ & $-2.858^{* * *}$ & $-4.653^{* * *}$ & $-3.930^{* * *}$ \\
& $(0.0705)$ & $(0.0749)$ & $(0.0957)$ & $(0.778)$ & $(0.633)$ \\
Nb. coauthors diff specialty & $2.768^{* * *}$ & $2.387^{* * *}$ & $1.741^{* * *}$ & $2.399^{* * *}$ & $5.090^{* *}$ \\
& $(0.307)$ & $(0.252)$ & $(0.272)$ & $(0.337)$ & $(2.449)$ \\
Nb. past moves & $1.595^{* * *}$ & $0.888^{* * *}$ & $1.233^{* * *}$ & $1.259^{* * *}$ & $1.280^{* * *}$ \\
& $(0.0675)$ & $(0.0597)$ & $(0.153)$ & $(0.121)$ & $(0.117)$ \\
Nb. of past Author's Fields & $-0.483^{* * *}$ & $0.303^{* * *}$ & $-0.642^{* * *}$ & $-1.040^{* * *}$ & $-0.895^{* * *}$ \\
& $(0.108)$ & $(0.113)$ & $(0.210)$ & $(0.187)$ & $(0.185)$ \\
Nb. of past sub-fields $(M . S . C$. codes $)$ & $1.579^{* * *}$ & $1.084^{* * *}$ & $1.301^{* * *}$ & $1.527^{* * *}$ & $1.342^{* * *}$ \\
& $(0.144)$ & $(0.108)$ & $(0.173)$ & $(0.127)$ & $(0.125)$ \\
Nb. of past coauthors & -0.0212 & $-0.159^{* * *}$ & $-0.238^{* * *}$ & $-0.125^{* *}$ & $-0.218^{* * *}$ \\
& $(0.0339)$ & $(0.0311)$ & $(0.0431)$ & $(0.0610)$ & $(0.0556)$ \\
Author Fixed Effects & No & Yes & Yes & Yes & Yes \\
Year Fixed Effects & Yes & Yes & Yes & Yes & Yes \\
Field Fixed Effects & Yes & Yes & Yes & Yes & Yes \\
University Fixed Effects & No & No & Yes & Yes & Yes \\
\hline R-squared & 0.140 & 0.099 & 0.118 & & \\
Observations & 551,655 & 551,655 & 296,538 & 260,007 & 268,892 \\
Number of Authors & 60,560 & 60,560 & 54,183 & 29,388 & 29,669 \\
\hline
\end{tabular}

Table 7: Effect of individual variables on mathematician's output

However, the number of past co-authors with different specialties has a positive impact. this is true independently of whether we account for unobserved author and university fixed effects. Moreover, the number of co-authors from different fields also has a positive impact when instrumented by its lagged value (column (5) of Table (7)). One interpretation is that collaboration with colleagues with a closely related competence is detrimental to total impact per author, but collaborating with mathematicians from a different main field is useful. It is remarkable that the coefficient of the number of coauthors from 
different fields more than doubles when it is instrumented by its lagged value. It shows that the simultaneity of author impact and the number of coauthors from different specialties is present. Actually, the unobserved time varying factors that increase the author impact are negatively correlated with the number of coauthors from different fields. Having published in the past in different fields or in different sub-subfields has opposite effects (except when we include author fixed effects but no university fixed effects). However, the overall effect is positive, meaning that the variety of sub-fields of publications in mathematics has a positive effect provided it stays within an identified field of mathematics. The number of past institutions is also clearly positive (coefficient of the number of past moves in Table (7)), which is consistent with our previous observations on the number of past subfields and of past co-authors: having been exposed to a wider spectrum of mathematical ideas has a positive effect on mathematical output.

\subsection{Effects of departments on individuals}

Then, an interesting question is the impact of location on mathematicians' output: how important are departments for the scientific productivity of their researchers? In order to study this question, we look into more details are the estimated values of the university fixed effects estimated before but not shown. Again, we use the data on the yearly production of authors as dependent variable. The coefficients of department dummies reflect the average output of researchers belonging to those departments over the 1984-2006 period. As authors are moving across departments, we can also control for author fixed effects and separate the effect of the department itself from the average quality of the mathematicians composing this department.

Table 8 shows the estimated mean effect of the 30 main mathematics departments (in terms of total output on the period) on their researchers using regressions of author impact on department dummies without author fixed effects (in column 1) and then with author fixed effects in columns 2 to 4 . Normalizing the constant so that the sum of the mean effect of the 30 departments under consideration is zero, the university effects just measure the "quality" of the 
department. When introducing author fixed effects, column 2 is for the whole sample period, while column 3 corresponds to the first period 1984-1994 and column 4 to the second period 1995-2006, in order to study the possible time variation in those effects.

Note that this analysis of the effect of departments on individuals, with fixed effects of the authors, is possible because there are many moves between departments. On average, each "active" mathematician in our base had 1.87 different locations over his lifetime, although this varies largely between countries.

Table 8 suggests that, generally speaking, the competitive advantage of elite mathematical departments does not seem to decrease between the first (before 1994) and the second part (after 1995) of our sample period. This contrasts with the findings of Kim et al. (2009) for economists (see also Agrawal and Goldfarb (2008)).

Table 8 also suggests that some elite departments have indeed a strong positive impact on their researchers. For instance being at N.Y.U. has a strong (although not significant) positive effect (13.17 weighted pages/year). However this effect becomes negative when the journal published by N.Y.U. (Communications in Pure and Applied Mathematics or CPAM) is taken out of the publications sample as shown in column 2 of Table 9.

The effect of local journals is also significant, albeit with a much smaller magnitude, for Paris 11 (its fixed effect falls from 22.98 to 16.32 when the geographically closest journal, Publications Mathématiques de l'I.H.E.S., is not considered). This does not necessarily mean that referees and editors are more friendly to local authors, but might possibly be explained simply by the fact that these authors are encouraged to publish in the local journal.

Note also that removing a journal also has an effect on the fixed effect of departments with no obvious relation to the journal. This can be explained by the fact that being in a given department encourages mathematicians to submit their paper to some journals more than to others. 


\subsection{Characteristics of departments}

We now consider more specifically the effect of different variables characterizing the 30 most important departments.

Table 10 shows the influence of different variables on authors' impact and number of articles published after controlling for author fixed effects. The University specialization index is defined as the sum of the squares of the proportions of the scientific output of the department in each field. It varies between 0 and 1 , and is close to 1 for highly specialized departments and small for general ones. It is defined based on the subfield (M.S.C., for Mathematics Subject Classification, as determined by Mathematical Reviews). The "Stability" variable is defined as the proportion of their total active life that mathematicians at a given department will spend there, so that it would be 1 for a department where everybody spends his whole active life, from first to last publication. It is an (inverse)indicator of mobility.

The first column shows the effect of the variables on the "impact" of authors taking into account the fixed effects of authors. Column 2 is similar but measures productivity by the number of pages published instead of the impact. The coefficient of the variable "Stability" is not significant. The coefficient of the department size is positive and significant: bigger departments attract better researchers even after controlling for authors fixed effects. The coefficient of the University specialization index is strongly positive: specialized departments stimulate the productivity of their researchers.

\subsection{U.S. departments}

Table 11 shows the influence of some variables that are specific to the U.S.: private vs. public universities, East Coast or West Coast, endowment per student. It also introduces a variable defined as Closeness which measures how "open" departments are, it is the mean over its members of the proportion of their "scientific life" they will spend in this department.

The effect of the endowment per student is remarkable. It is strongly positive without authors fixed effects, meaning that rich universities can attract better researchers. However it is negative (but not significantly) when authors 
fixed effects are taken into account. This is rather counter-intuitive since a higher endowment could imply lower teaching loads and therefore more time for research. A possible explanation is simply that, once researchers have obtained a position in a well-endowed university, they have weaker incentives to publish first-rate articles. A similar result was obtained in economics by Ellison (2010), who finds that after they have received their tenure, the economists of top U.S. departments slow down their publications pace in top journals.

It is also interesting to note that the East Coast has a significant positive effect over the Midwest (2 standard deviations). The West Coast stands in between.

Finally the effect of public universities is slightly negative but not significant. This could be attributed to higher teaching loads than in private universities. The difference becomes significant when taking into account the endowment per student, which is concentrated almost only on private universities.

\subsection{The impact of age: variations between countries}

It is often believed that the productivity of mathematicians declines rapidly with age. We show here that this is not the case, but that there are important crosscountry differences in the life-cycle productivities of mathematicians. These differences might be explained by features such as the ages at which long-term or permanent positions can be obtained, the grant systems, and more generally the nature of the incentives given to scientists, as well as the degree of mobility between institutions, and the variability of teaching loads. The following figure represents a cross-country comparison of the profiles of scientific productivity of mathematicians as a function of their "age", defined as the number of years that have elapsed since their first publication.

Figure 1 shows how "age" - the number of years after the first publication influences the production of mathematicians in different countries. Obviously, there are important differences in the average scientific output of researchers between countries. However the allocation of this output through time also varies strongly between countries. The graphs indicate that some countries are better than other at helping their researchers to remain active. For instance, 

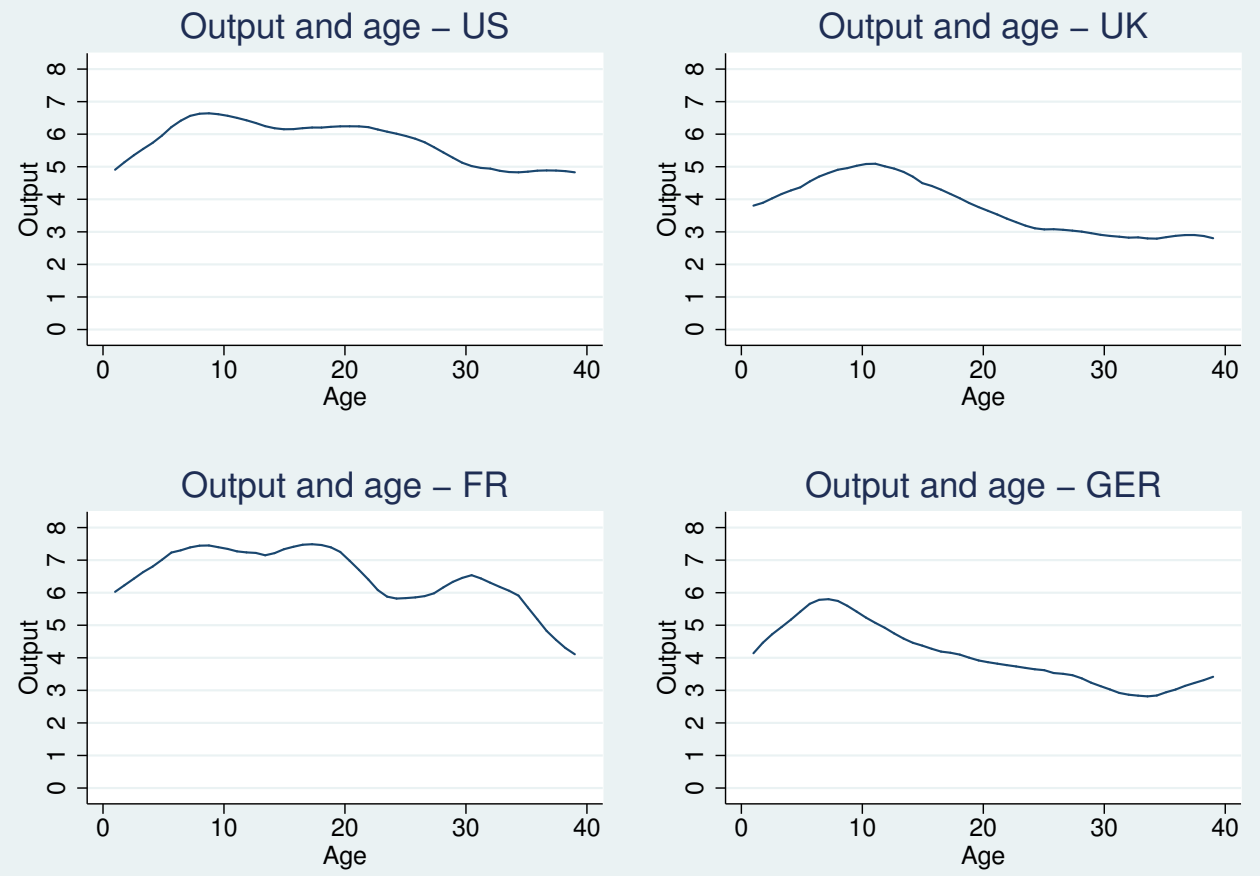

Figure 1: Variation of productivity with age, selected countries

in Germany, the peak productivity is reached at a younger age than in Britain or the United States, and decrease in production is then steeper. However, the overall picture shows that there is much more variation of productivity across countries than across ages of mathematicians within a country. We can interpret this finding in terms of life cycle evolution of the mathematician's productivity. However there can also be cohort-effects as found by Oyer (2006). But the length of the time period covered by our data allows us to be confident that the age effects that we have identified are indeed present. A possibility remains that the younger cohorts observed in the 2000s would not behave as their older cohorts during the same period when they will grow older. 


\section{Conclusion}

The analysis presented here has some interesting implications for individual researchers, departments, or in terms of scientific policy.

Our results shed some light on the possibility for the academic community to detect promising mathematicians from their current production. The main indicator of future success for a young mathematician is obviously the quality of his current publications. However our results tend to indicate some less obvious criteria, which can be measured over the first few years of activity, and are correlated with a higher future scientific output. Among those, we can cite a wide spectrum of interests. The capability to collaborate with colleagues having different mathematical interests is a good predictor of success. In other words, a strong focus on one area, which is sometimes presented as a way for young scientists to gain a head start, could be counter-productive in the longer term. The total number of collaborations, on the other hand, has more complex implications. Having a large number of past coauthors appears positively correlated to the output, but a large number of current coauthors appears to have a negative impact, probably meaning that increasing co-authorship is inefficient in the short run but has a positive effect in the longer run.

Then, our results also suggest suitable policies or recommendations to improve a mathematics department or mathematical research on a large scale.

For example, encouraging mobility appears to be a way to improve both the quality of a department and the scientific output of its members. On the other hand, encouraging members of a department to collaborate more does not appear to be efficient, except if the collaboration is with colleagues from different areas. This suggests that reading groups or seminars bringing together mathematicians with different specialties could be a way to broaden their interests and to improve their output.

Concentration on some subfields has mixed effects: it appears to lower the output of the department through the hiring of less productive mathematicians, but allows to get better papers from mathematicians with a given talent.

Concerning the global mathematical research, again a high level of mobility seems to have positive effects. By contrast, allocating large subsidies to some 
departments appears to be useless: it may attract the more active researchers to the richer departments, but does not increase their output when taking in account authors fixed effects.

An important question, for which we do not have a definite answer, is how important it is to train young researchers in the most active departments. One problem here is that it is difficult to distinguish the quality of the training from the intrinsic "talent" of mathematicians.

Finally, an extension of our results to other scientific areas than mathematics would probably be hazardous. There are many differences across sciences: for instance the importance of funding is fundamentally different between experimental fields and the more theoretical ones. It would be interesting to check to what extent our findings for mathematics are also valid in other fields, but this would require the availability of an exhaustive and easy-to-use data set on publications in other fields, comparable to Mathematical Reviews for mathematics.

\section{References}

Adler, Robert, John Ewing, and Peter Taylor (2009), "Citation statistics: A report from the International Mathematical Union (IMU) in cooperation with the International Council of Industrial and Applied Mathematics (ICIAM) and the Institute of Mathematical Statistics (IMS)." Statist. Sci., 24, 1-14, URL http://dx.doi.org/10.1214/09-STS285.

Agrawal, A. and A. Goldfarb (2008), "Restructuring research: communication costs and the democratization of university innovation." American Economic Review, 98, 1578-1590.

Borjas, G.J. and K.B. Doran (2012), "The collapse of the soviet union and the productivity of american mathematicians." Technical report, National Bureau of Economic Research.

Combes, P.P. and L. Linnemer (2003), "Where are the economists who publish? Publication concentration and rankings in Europe based on cumulative publications." Journal of the European Economic Association, 1, 1250-1308. 
Coupé, T. (2003), "Revealed performances: Worldwide rankings of economists and economics departments, 1990-2000." Journal of the European Economic Association, 1, 1309-1345.

Davis, G. (1997), "Mathematicians and the market." Notices Amer. Math. Soc., 44, 1307-1315.

Ellison, Glenn (2010), "How does the market use citation data? the Hirsch index in economics." CESifo Working Paper Series 3188, CESifo Group Munich, URL http://ideas.repec.org/p/ces/ceswps/_3188.html.

Ellison, Glenn (2011), "Is peer review in decline?" Economic Inquiry, 49, 635657.

Ellison, Glenn (2012), "Assessing computer scientists using citation data." Technical report, URL http://economics.mit.edu/files/7784.

Hill, Derek, Alan I. Rapoport, Rolf F. Lehming, and Robert K. Bell (2007), "Changing U.S. output of scientific articles: 19882003." Technical Report NSF 07-320, National Science Foundation, Division of Science Resources Statistics.

Hirsch, B.T., R. Austin, J. Brooks, and J.B. Moore (1984), "Economics departmental rankings: Comment." The American Economic Review, 74, 822-826.

Hirsch, J.E. (2005), "An index to quantify an individual's scientific research output." Proceedings of the National Academy of Sciences, 102, 16569.

Jones, B. (2010), "As science evolves, how can science policy?" Technical report, National Bureau of Economic Research.

Kim, E.H., A. Morse, and L. Zingales (2009), "Are elite universities losing their competitive edge?" Journal of Financial Economics.

Korevaar, JC (1996), "Validation of bibliometric indicators in the field of mathematics." Scientometrics, 37, 117-130.

Laband, D.N. and R.D. Tollison (2000), "Intellectual collaboration." Journal of Political Economy, 108, 632-662. 
Levin, S.G. and P.E. Stephan (1991), "Research productivity over the life cycle: evidence for academic scientists." The American Economic Review, 81, 114132.

Lotka, A.J. (1926), "The frequency distribution of scientific productivity." Journal of the Washington Academy of Science, 16, 317-323.

Neary, J.P., J.A. Mirrlees, and J. Tirole (2003), "Evaluating economics research in Europe: An introduction." Journal of the European Economic Association, $1,1239-1249$.

Oyer, P. (2006), "Initial labor market conditions and long-term outcomes for economists." The Journal of Economic Perspectives, 20, 143-160.

Palacios-Huerta, I. and O. Volij (2004), "The measurement of intellectual influence." Econometrica, 72, 963-977.

Stephan, P. (2008), "Job Market Effects on Scientific Productivity." Conferences on New Political Economy, 25, 11-29.

Waldinger, Fabian (2012), "Peer effects in science - evidence from the dismissal of scientists in nazi germany." The Review of Economic Studies, 79, 838-861.

Wuchty, S., B.F. Jones, and B. Uzzi (2007), "The increasing dominance of teams in production of knowledge." Science, 316, 1036-1039.

\section{A Additional Tables}

\section{B Results based on the Impact factor}

The data presented in this section are similar to those obtained in other parts of the paper, however the basic indicators are based on the IF rather than on $M C Q$. More precisely, the weight attributed to each article is equal to the number of its pages times the $I F$ of the journal where it is published, rather than the square of the $M C Q$.

The Table 19 is the analog of Table 8. 
Similarly, we have the analog of Table 9 in Table 20 with the impact of authors based on the IF.

We now consider the factors playing a part in a mathematician's scientific productivity. Table 21 is the analog of Table 10 based on the IF rather than the $M C Q$.

The analog of Table 11 with the impact of authors based on the IF is in Table 22 . Finally, Table 23 is the analog of Table 7 based on the IF.

\section{More on the data}

Tables 24 and 25 contains the list of journals used here. With each journal we list the total number of pages published in the sample period, the number of articles, the 2007 M.C.Q., the mean number of pages by article, and the mean number of authors by article. The code used for each journal (in the first column) should make it easy, for those familiar with the mathematical literature, to identify each journal. 


\begin{tabular}{|c|c|c|c|c|}
\hline & (1) & $(2)$ & (3) & (4) \\
\hline VARIABLES & Author & Author & Author & Author \\
\hline IAS Princeton & Impact & Impact & Impact & Impact \\
\hline IAS Princeton & $\begin{array}{l}16.05 \text { bar } \\
(1.782)\end{array}$ & $\begin{array}{l}-1.001 \\
(4.847)\end{array}$ & $\begin{array}{l}-1.194 \\
(8.961)\end{array}$ & $\begin{array}{l}-9.333 \\
(7.363)\end{array}$ \\
\hline Princeton & $10.72^{* * *}$ & -5.216 & -2.509 & -7.118 \\
\hline Harvard & $8.922^{* * * *}$ & $\begin{array}{l}-0.818 \\
(4816)\end{array}$ & $\begin{array}{c}2.318 \\
(9.373)\end{array}$ & $\begin{array}{c}-17.97^{* *} \\
(7.290)\end{array}$ \\
\hline U Paris 11 & $6.030 * * *$ & $\begin{array}{l}-8.928 \\
(7.109)\end{array}$ & $\begin{array}{l}5.648 \\
(1279)\end{array}$ & -8.991 \\
\hline NYU & $4.576^{* * *}$ & 7.692 & $16.00^{*}$ & -9.464 \\
\hline U Chicago & $2.713^{* *}$ & $\begin{array}{c}(4.710) \\
2.851\end{array}$ & $\begin{array}{l}(8.833) \\
1.674\end{array}$ & $\begin{array}{l}(7.901) \\
-7.482\end{array}$ \\
\hline & $(1.125)$ & $(4.724)$ & $(9.000)$ & $(7.220)$ \\
\hline MIT & $\begin{array}{c}0.510 \\
(0.902)\end{array}$ & $\begin{array}{l}-3.570 \\
(4.476)\end{array}$ & $\begin{array}{l}-3.369 \\
(8.806)\end{array}$ & $\begin{array}{c}-15.93^{* *} \\
(6.697)\end{array}$ \\
\hline Columbia & $\begin{array}{c}0.296 \\
(1.300)\end{array}$ & $\begin{array}{c}0.843 \\
(5.730)\end{array}$ & $\begin{array}{l}-2.620 \\
(10.77)\end{array}$ & $\begin{array}{c}-13.02 \\
(8.782)\end{array}$ \\
\hline UC Berkeley & $\begin{array}{c}-3.498^{* * * *} \\
(0.836)\end{array}$ & $\begin{array}{c}-8.892^{* * *} \\
(4.408)\end{array}$ & $\begin{array}{l}-10.12 \\
(8.815)\end{array}$ & $\begin{array}{c}-15.67^{* *} \\
(6.976)\end{array}$ \\
\hline $\mathrm{U}$ Paris 6 & $-3.262^{* * *}$ & -6.691 & 0.0252 & -8.272 \\
\hline UCLA & -1.423 & $\begin{array}{l}(7.158) \\
-0.517 \\
(5.077)\end{array}$ & $\begin{array}{c}(12.85) \\
1.788 \\
0.044)\end{array}$ & $\begin{array}{l}(11.75) \\
-8.791\end{array}$ \\
\hline Stanford & $-4.031 * * *$ & -5.427 & $\begin{array}{l}(9.744) \\
-2.757\end{array}$ & $-15.62^{* *}$ \\
\hline U Michigan & $\begin{array}{c}(0.997) \\
-4.579 * * * \\
(0.961)\end{array}$ & $\begin{array}{c}(4.684) \\
-11.04 * * \\
(4.594)\end{array}$ & $\begin{array}{c}(9.188) \\
-17.80^{*} \\
(9.333)\end{array}$ & $\begin{array}{l}-16.59^{* *} \\
(6.919)\end{array}$ \\
\hline Rutgers & $\begin{array}{c}-3.688 * * * \\
(1.001)\end{array}$ & $\begin{array}{l}-1.294 \\
(5.270)\end{array}$ & $\begin{array}{c}2.956 \\
(10.12)\end{array}$ & $\begin{array}{l}-9.720 \\
(8.748)\end{array}$ \\
\hline Purdue & $\begin{array}{c}-3.523^{* * * *} \\
(1.018)\end{array}$ & $\begin{array}{c}0.862 \\
(5.672)\end{array}$ & $\begin{array}{c}11.04 \\
(9.342)\end{array}$ & $\begin{array}{c}-24.68^{* * *} \\
(10.94)\end{array}$ \\
\hline U Minnesota & $\begin{array}{c}-5.918^{* * * *} \\
0.942)\end{array}$ & $\begin{array}{c}-0.841 \\
(4.903)\end{array}$ & $\begin{array}{c}5.120 \\
(9.166)\end{array}$ & $\begin{array}{c}-6.019 \\
(7.638)\end{array}$ \\
\hline U Maryland & $\begin{array}{c}-4.042^{* * *} * \\
(1.033)\end{array}$ & $\begin{array}{l}-3.216 \\
(5.408)\end{array}$ & $\begin{array}{c}-0.451 \\
(9.438)\end{array}$ & $\begin{array}{l}-4.440 \\
(10.03)\end{array}$ \\
\hline U Toronto & $\begin{array}{c}-4.372^{* * *} \\
(1.101)\end{array}$ & $\begin{array}{l}1.161 \\
(5.793)\end{array}$ & $\begin{array}{c}5.179 \\
(11.73)\end{array}$ & $\begin{array}{l}-6.598 \\
(8.163)\end{array}$ \\
\hline Ohio State U & $\begin{array}{c}-4.582^{* * *} \\
(1.073)\end{array}$ & $\begin{array}{l}-6.306 \\
(5.446)\end{array}$ & $\begin{array}{l}-10.32 \\
(10.03)\end{array}$ & $\begin{array}{l}-8.295 \\
(8.518)\end{array}$ \\
\hline $\mathrm{U}$ Wisconsin & $\begin{array}{c}-6.897 * * * \\
(0.994)\end{array}$ & 0 & 0 & 0 \\
\hline Constant & $\begin{array}{c}27.26^{* * * *} \\
(1.758)\end{array}$ & $\begin{array}{c}28.51^{* * *} \\
(6.261)\end{array}$ & $\begin{array}{c}34.82^{* * *} \\
(10.41)\end{array}$ & $\begin{array}{c}22.46^{* *} \\
(9.662)\end{array}$ \\
\hline $\begin{array}{l}\text { Author Fixed Effects } \\
\text { R-squared }\end{array}$ & No & $\begin{array}{l}\text { Yes } \\
0.417\end{array}$ & $\begin{array}{l}\text { Yes } \\
0.471\end{array}$ & $\begin{array}{l}\text { Yes } \\
0.450\end{array}$ \\
\hline tions & 34,291 & 34,291 & 14,868 & 19,423 \\
\hline & & & $<1995$ & \\
\hline
\end{tabular}

Table 8: Fixed effects of major departments 


\begin{tabular}{lccccc}
\hline \multirow{2}{*}{ VARIABLES } & $(1)$ & $(2)$ & $(3)$ & $(4)$ & $(5)$ \\
& Author & Author & Author & Author & Author \\
& Impact & Impact & Impact & Impact & Impact \\
\hline Princeton & -1.697 & -2.648 & $-6.465^{*}$ & -3.700 & -1.443 \\
& $(3.779)$ & $(3.694)$ & $(3.519)$ & $(3.449)$ & $(3.793)$ \\
U Paris 11 & -4.269 & -4.370 & 2.553 & -7.670 & -5.237 \\
& $(7.844)$ & $(7.668)$ & $(7.304)$ & $(7.159)$ & $(7.873)$ \\
NYU & $12.61^{* * *}$ & -3.225 & $12.56^{* * *}$ & $12.88^{* * *}$ & $12.60^{* * *}$ \\
& $(4.655)$ & $(4.551)$ & $(4.335)$ & $(4.249)$ & $(4.672)$ \\
IAS Princeton & 2.674 & 1.986 & 1.025 & -3.113 & 3.282 \\
& $(5.145)$ & $(5.029)$ & $(4.790)$ & $(4.695)$ & $(5.163)$ \\
Constant & $31.62^{* * *}$ & $26.99^{* * *}$ & $30.93^{* * *}$ & $31.79 * * *$ & $30.81^{* * *}$ \\
& $(7.895)$ & $(7.718)$ & $(7.352)$ & $(7.206)$ & $(7.924)$ \\
\hline R-squared & 0.013 & 0.012 & 0.013 & 0.016 & 0.013 \\
Observations & 19,547 & 19,547 & 19,547 & 19,547 & 19,547 \\
Number of Authors & 7,373 & 7,373 & 7,373 & 7,373 & 7,373 \\
Removed & None & CPAM & Annals & IHES & E.N.S. \\
\hline
\end{tabular}

Table 9: Fixed effects of a selection of major departments, with and without local journals removed 


\begin{tabular}{lcccc}
\hline & $(1)$ & $(2)$ & $(3)$ & $(4)$ \\
VARIABLES & Author Impact & Author Impact & Nb. Articles & Nb. Articles \\
\hline \multirow{4}{*}{ Nb. of coauthors } & $-4.051^{* * *}$ & $-4.024^{* * *}$ & $0.0296^{* * *}$ & $0.0291^{* * *}$ \\
& $(0.122)$ & $(0.121)$ & $(0.00255)$ & $(0.00254)$ \\
Age & $0.551^{* * *}$ & $0.573^{* * *}$ & $0.0226^{* * *}$ & $0.0219^{* * *}$ \\
& $(0.0715)$ & $(0.0714)$ & $(0.00163)$ & $(0.00165)$ \\
Age $^{2}$ & $-0.0245^{* * *}$ & $-0.0253^{* * *}$ & $-0.000802^{* * *}$ & $-0.000803^{* * *}$ \\
& $(0.00339)$ & $(0.00333)$ & $(8.27 \mathrm{e}-05)$ & $(8.21 \mathrm{e}-05)$ \\
Age $^{3}$ & $0.000229^{* * *}$ & $0.000231^{* * *}$ & $7.65 \mathrm{e}-06^{* * *}$ & $7.64 \mathrm{e}-06^{* * *}$ \\
& $(4.93 \mathrm{e}-05)$ & $(4.86 \mathrm{e}-05)$ & $(1.26 \mathrm{e}-06)$ & $(1.24 \mathrm{e}-06)$ \\
Univ. Specialization Index & $3.155^{* * *}$ & $3.075^{* * *}$ & $3.82 \mathrm{e}-05$ & 0.0150 \\
& $(0.999)$ & $(0.945)$ & $(0.0272)$ & $(0.0281)$ \\
Size of University & $0.0315^{* * *}$ & $-0.0278^{* *}$ & $0.000724^{* * *}$ & $0.00146^{* * *}$ \\
& $(0.00767)$ & $(0.0140)$ & $(0.000161)$ & $(0.000303)$ \\
Stability & 2.026 & $4.855^{* * *}$ & 0.0480 & 0.0551 \\
& $(1.899)$ & $(1.733)$ & $(0.0421)$ & $(0.0446)$ \\
\hline Author Fixed Effects & Yes & Yes & Yes & Yes \\
Year Fixed Effects & Yes & Yes & Yes & Yes \\
Field Fixed Effects & Yes & Yes & Yes & Yes \\
University Fixed Effects & No & Yes & No & Yes \\
R-squared & 0.011 & 0.020 & 0.005 & 0.008 \\
Observations & 138,707 & 138,707 & 138,707 & 138,707 \\
Number of Authors & 30,266 & 30,266 & 30,266 & 30,266 \\
\hline
\end{tabular}

Table 10: Effect of individual and department variables on authors' impacts and number of articles 


\begin{tabular}{lccc}
\hline \multirow{2}{*}{ VARIABLES } & $(1)$ & $(2)$ & $(3)$ \\
& Author Impact & Author Impact & Author Impact \\
\hline \multirow{2}{*}{ Nb. of coauthors } & $-5.967^{* * *}$ & $-4.530^{* * *}$ & $-4.524^{* * *}$ \\
& $(0.234)$ & $(0.256)$ & $(0.254)$ \\
Age & $1.286^{* * *}$ & $0.513^{* * *}$ & $0.482^{* * *}$ \\
& $(0.103)$ & $(0.143)$ & $(0.143)$ \\
Age $^{2}$ & $-0.0509^{* * *}$ & $-0.0205^{* * *}$ & $-0.0203^{* * *}$ \\
& $(0.00502)$ & $(0.00659)$ & $(0.00656)$ \\
Age $^{3}$ & $0.000514^{* * *}$ & 0.000141 & 0.000132 \\
& $(6.71 \mathrm{e}-05)$ & $(9.24 \mathrm{e}-05)$ & $(9.23 \mathrm{e}-05)$ \\
Univ. Specialization Index & -0.651 & 4.010 & 2.043 \\
& $(1.891)$ & $(2.807)$ & $(2.335)$ \\
Size of University & $0.0993^{* * *}$ & 0.0195 & -0.0321 \\
& $(0.0101)$ & $(0.0163)$ & $(0.0282)$ \\
Closeness & $-26.26^{* * *}$ & -3.308 & 3.965 \\
& $(3.574)$ & $(5.947)$ & $(4.009)$ \\
Private University & $4.511^{* * *}$ & $2.072^{*}$ & \\
& $(0.717)$ & $(1.128)$ & \\
Endowment per Student & $4.615^{* * *}$ & -2.256 & \\
& $(1.276)$ & $(1.611)$ & \\
East Coast University & $4.081^{* * *}$ & 1.708 & \\
& $(0.619)$ & $(1.082)$ & \\
West Coast University & $2.784^{* * *}$ & 0.215 & \\
& $(0.858)$ & $(1.498)$ & \\
\hline Author Fixed Effects & No & Yes & Yes \\
Year Fixed Effects & Yes & Yes & Yes \\
Field Fixed Effects & Yes & Yes & Yes \\
University Fixed Effects & No & No & Yes \\
R-squared & 0.127 & 0.431 & 0.436 \\
Observations & 52,599 & 52,599 & 52,599 \\
\hline
\end{tabular}

Table 11: The determinants of mathematicians' scientific output, without/with fixed effects, US only 


\begin{tabular}{|c|c|c|c|c|c|}
\hline \multicolumn{6}{|l|}{ Field } \\
\hline & Authors/paper & Pages/paper & - Mean Impact & \# Authors & \# articles \\
\hline Algebra & 1.98 & 23.73 & 31.34 & 2463 & 8454 \\
\hline Analysis & 2.07 & 19.70 & 16.46 & 8438 & 31194 \\
\hline DynSys & 2.32 & 23.61 & 22.65 & 1420 & 4798 \\
\hline GeomAlg & 1.84 & 23.36 & 36.43 & 4101 & 16720 \\
\hline GeomDiff & 1.99 & 22.69 & 28.72 & 5814 & 23544 \\
\hline Numeric & 2.30 & 19.75 & 10.17 & 4638 & 17420 \\
\hline PDE & 2.10 & 23.13 & 21.32 & 5898 & 25390 \\
\hline Physics & 2.47 & 21.59 & 12.79 & 4455 & 12362 \\
\hline ProbaStat & 2.13 & 18.37 & 8.16 & 10244 & 41721 \\
\hline Topology & 1.87 & 25.13 & 39.09 & 2238 & 9065 \\
\hline
\end{tabular}

Table 12: Comparative characteristics of articles in different fields

\begin{tabular}{|c|c|c|c|c|c|c|c|c|}
\hline & \multicolumn{8}{|c|}{ Country } \\
\hline Years & $\mathrm{CA}$ & FR & GER IL IT & JAP & PRC I & RUS SP & UK I & US \\
\hline 1984-86 & 62 & 51 & 475739 & 29 & 65 & 2233 & 48 & 25 \\
\hline $1987-90$ & 58 & 50 & $5466 \quad 40$ & 36 & 58 & $25 \quad 39$ & 52 & 26 \\
\hline $1991-94$ & 60 & 50 & 546248 & 31 & 51 & 5536 & 53 & 28 \\
\hline $1995-98$ & 58 & 49 & 546144 & 36 & 49 & $72 \quad 38$ & 54 & 32 \\
\hline 1999-02 & 67 & 47 & 576346 & 41 & 39 & $\begin{array}{ll}76 \quad 42\end{array}$ & 56 & 37 \\
\hline 2003-06 & 64 & 51 & $\begin{array}{llll}58 & 64 & 45\end{array}$ & 48 & 51 & 7943 & 60 & 37 \\
\hline Average & 62 & 49 & $\begin{array}{lll}56 & 63 & 45\end{array}$ & 39 & 48 & $\begin{array}{ll}66 & 41\end{array}$ & 55 & 32 \\
\hline
\end{tabular}

Table 13: Proportions (in \% ) of international collaborations over time 


\begin{tabular}{lrrrrrrrrrrrrrr}
\hline $\begin{array}{l}\text { Country } \\
\text { of first } \\
\text { location }\end{array}$ & CA & FR & GER & IL & IT JAP & OTH PRC RUS & SP & UK & US Total years \\
\hline CA & 66.9 & 1.8 & 0.6 & 1.6 & 0.2 & & 4.3 & 0.1 & & 0.9 & 1.2 & 22.5 & 2226 \\
FR & 0.6 & 90.0 & 1.1 & 0.2 & 0.6 & 0.2 & 2.3 & & & 1.0 & 0.6 & 3.4 & 5403 \\
GER & 1.0 & 1.6 & 81.4 & & 0.5 & 0.1 & 5.2 & 0.2 & & 0.0 & 2.7 & 7.2 & 5042 \\
IL & 3.3 & 0.8 & 0.2 & 68.7 & & & 2.3 & & 0.1 & & 2.3 & 22.2 & 1204 \\
IT & 0.2 & 2.6 & 1.0 & & 91.6 & & 2.0 & & & 0.3 & 0.5 & 1.8 & 2192 \\
JAP & & & 1.0 & & 0.1 & 92.7 & 2.2 & 0.9 & & & 0.2 & 2.8 & 2020 \\
OTH & 0.8 & 2.3 & 2.2 & 0.1 & 0.4 & 0.1 & 83.9 & 0.8 & & 0.1 & 1.3 & 8.0 & 12341 \\
PRC & 2.6 & 1.1 & 0.8 & 0.1 & 0.2 & & 3.8 & 80.5 & & 0.1 & 0.6 & 10.2 & 1914 \\
RUS & 2.1 & 0.6 & 2.1 & & 1.2 & & 7.0 & & 61.2 & & 9.4 & 16.4 & 330 \\
SP & & 0.7 & 0.3 & & 0.0 & & 0.9 & 0.2 & & 96.6 & 0.4 & 0.8 & 2349 \\
UK & 2.2 & 1.7 & 2.3 & 0.1 & 1.1 & 0.2 & 11.5 & 1.5 & & 0.2 & 68.8 & 10.3 & 3618 \\
US & 2.2 & 1.0 & 0.9 & 1.0 & 0.8 & 0.2 & 6.8 & 0.7 & 0.0 & 0.5 & 1.6 & 84.3 & 22882 \\
Total years & 2455 & 5701 & 4848 & 1173 & 2384 & 1971 & 13326 & 1930 & 210 & 2508 & 3371 & 25921 & 65798 \\
\hline
\end{tabular}

Table 14: Transition matrix of mathematicians: locations of the mathematicians who have started in a given country. Numbers in columns do not sum to 100 , due to imbalance of flows across countries.

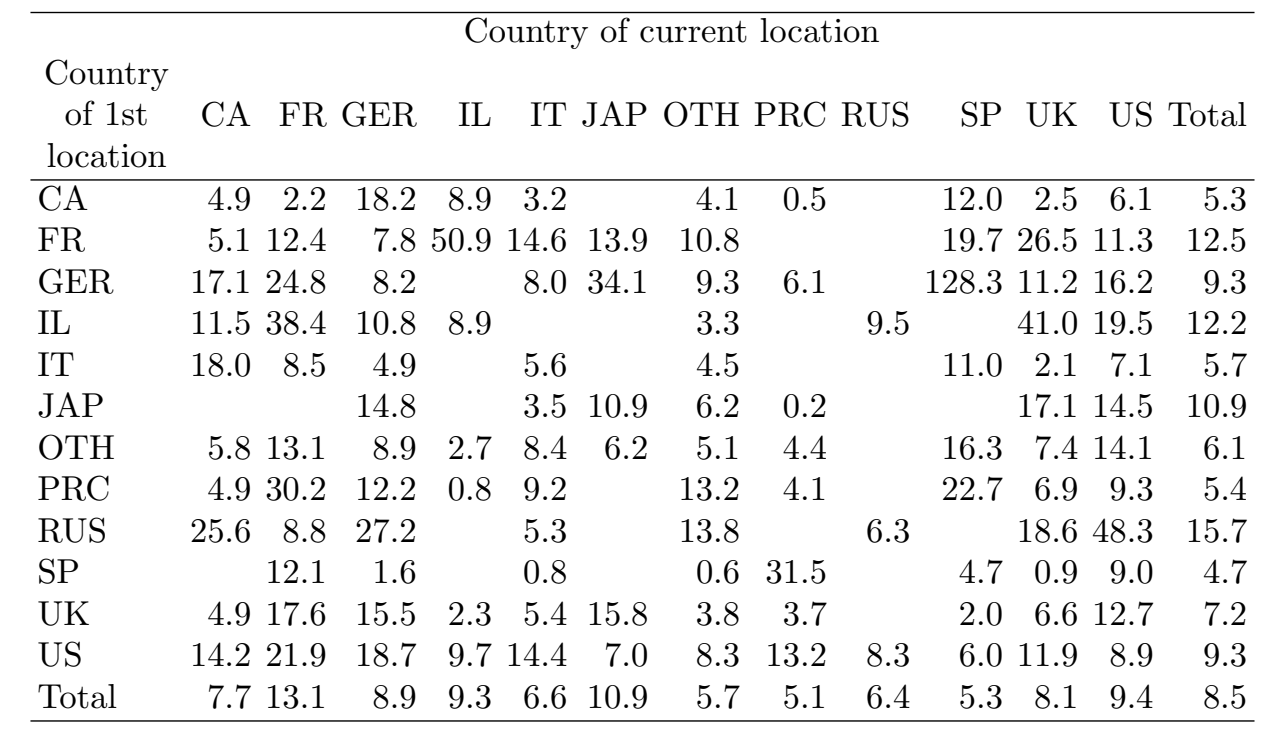

Table 15: Mean impact of mathematicians depending on country of first location and current country 


\begin{tabular}{|c|c|c|c|c|c|c|c|c|c|c|c|c|c|}
\hline \multirow[b]{2}{*}{ From } & \multicolumn{13}{|c|}{ To } \\
\hline & $\mathrm{CA}$ & $\mathrm{FR}$ & GER & IL & IT & JAP & OTH & PRC & RUS & SP & UK & US & Tota \\
\hline$\overline{\mathrm{CA}}$ & 0 & 9 & 5 & 5 & 3 & 1 & 38 & 10 & 1 & 2 & 16 & 140 & 230 \\
\hline $\mathrm{FR}$ & 10 & 0 & 12 & 7 & 16 & 2 & 40 & & 1 & 12 & 12 & 62 & 180 \\
\hline GER & 13 & 37 & 0 & 2 & 10 & 13 & 115 & & 3 & 1 & 48 & 114 & 361 \\
\hline $\mathrm{T}$ & 7 & 6 & 2 & 0 & 0 & 0 & 6 & 0 & 0 & 0 & 0 & 73 & 94 \\
\hline $\mathrm{T}$ & 3 & 10 & 5 & 0 & 0 & 0 & 19 & 2 & 0 & 1 & 6 & 26 & 72 \\
\hline JAP & 0 & 2 & 12 & 0 & 1 & 0 & 7 & 5 & 0 & 0 & 1 & 18 & 46 \\
\hline OTH & 35 & 82 & 100 & 3 & 18 & 9 & 0 & 53 & 8 & 8 & 65 & 315 & 696 \\
\hline${ }^{\circ} \mathrm{RC}$ & 12 & 5 & 4 & 0 & 5 & 2 & 34 & 0 & 0 & 0 & 12 & 43 & 117 \\
\hline RUS & 2 & 12 & 14 & 6 & 5 & 0 & 28 & 0 & 0 & 2 & 17 & 49 & 135 \\
\hline $\mathrm{sP}$ & 0 & 2 & 3 & 0 & 1 & 0 & 10 & 0 & 2 & 0 & 5 & 6 & 29 \\
\hline JK & 12 & 18 & 13 & 1 & 7 & 1 & 67 & 14 & 2 & 3 & 0 & 91 & 229 \\
\hline US & 114 & 65 & 90 & 88 & 40 & 23 & 319 & 42 & 7 & 17 & 85 & 0 & 890 \\
\hline Total & 208 & 248 & 260 & 112 & 106 & 51 & 683 & 137 & 24 & 46 & 267 & 937 & 3,079 \\
\hline
\end{tabular}

Table 16: Number of "permanent" moves from one country to another

\begin{tabular}{lrrrrrrrrrrr}
\hline & \multicolumn{11}{c}{ To } \\
From & CA & FR & GER & IL & IT & JAP & PRC RUS & SP & UK & US \\
\hline CA & 4.9 & 9.6 & 6.5 & 2.6 & 12.4 & 21.3 & 4.6 & 4.2 & 3.2 & 6.3 & 9.1 \\
FR & 9.3 & 12.4 & 20.8 & 22.4 & 7.9 & 8.4 & 12.5 & 1.5 & 28.5 & 16.1 & 25.5 \\
GER & 23.3 & 15.4 & 8.2 & 13.0 & 9.2 & 17.5 & 5.3 & 3.7 & 4.8 & 12.0 & 16.7 \\
IL & 11.6 & 5.6 & 7.8 & 8.9 & & & & & & & 19.0 \\
IT & 4.7 & 9.9 & 13.1 & & 5.6 & & 11.6 & & 1.7 & 10.6 & 14.5 \\
JAP & & 2.4 & 10.6 & & 16.6 & 10.9 & 9.3 & & & 8.3 & 26.8 \\
PRC & 4.2 & 21.2 & 9.6 & & 8.4 & 0.6 & 13.2 & & & 3.2 & 9.3 \\
RUS & 0.6 & 14.3 & 10.0 & 3.2 & 3.3 & & & 6.3 & 21.3 & 9.1 & 19.1 \\
SP & & 7.9 & 14.2 & & 2.5 & & & 21.3 & 4.7 & 15.0 & 4.1 \\
UK & 9.0 & 12.7 & 15.6 & 40.9 & 12.2 & 21.3 & 11.1 & 1.7 & 7.4 & 6.6 & 15.9 \\
US & 14.2 & 26.9 & 18.8 & 15.7 & 17.4 & 9.4 & 16.1 & 9.7 & 11.3 & 15.0 & 8.9 \\
\hline
\end{tabular}

Table 17: Mean impact over lifetime of mathematicians moving from one country to another 


\begin{tabular}{|c|c|c|c|c|c|}
\hline University & Rank & Size & $\begin{array}{c}\text { Share } \\
\text { 1st Author }\end{array}$ & $\begin{array}{c}\text { Share } \\
5 \text { Authors }\end{array}$ & $\begin{array}{c}\text { Share } \\
10 \text { authors }\end{array}$ \\
\hline Princeton & 1 & 96.9 & 5.9 & 19.5 & 30.3 \\
\hline Paris $11(\mathrm{~F})$ & & 105.5 & 11.8 & 25.1 & 36.2 \\
\hline MIT & & 123.2 & 11 & 24.1 & 34.2 \\
\hline NYU & & 102.5 & 6.2 & 19.8 & 29.1 \\
\hline Berkeley & 5 & 146 & 4.1 & 14.6 & 23.4 \\
\hline Harvard & 6 & 64.9 & 10 & 29.9 & 41.4 \\
\hline Paris $6(\mathrm{~F})$ & & 143.1 & 13.5 & 22 & 28.5 \\
\hline Chicago & 8 & 81.1 & 7 & 21.4 & 31.8 \\
\hline UCLA & 9 & 93.8 & 7.6 & 26.9 & 36.2 \\
\hline Stanford & 10 & 106.7 & 6.1 & 21 & 34.3 \\
\hline Michigan & 11 & 111.8 & 4.6 & 15.7 & 24.9 \\
\hline Rutgers & 12 & 104.2 & 6 & 22.2 & 33.2 \\
\hline Purdue & 13 & 95.5 & 5.9 & 22.6 & 35.9 \\
\hline Minnesota & 14 & 116.5 & 5.4 & 18.3 & 30.3 \\
\hline Maryland & 15 & 95.6 & 8.3 & 28.5 & 42.4 \\
\hline IAS Princeton & 16 & 33.2 & 12 & 30.9 & 41 \\
\hline Toronto & 17 & 78.7 & 14.5 & 29.8 & 42.2 \\
\hline Ohio State & 18 & 86 & 7 & 19.5 & 33.1 \\
\hline Columbia & 19 & 57.2 & 8.9 & 26.9 & 42.4 \\
\hline Wisconsin & 20 & 101.3 & 5.9 & 20.4 & 33.5 \\
\hline Cornell & 21 & 106.5 & 5.6 & 22.9 & 35.2 \\
\hline Oxford (UK) & 22 & 80.6 & 8.5 & 28.9 & 40.5 \\
\hline Paris $7(\mathrm{~F})$ & 23 & 49.5 & 6.4 & 23.8 & 38.2 \\
\hline Caltech & 24 & 54.2 & 10 & 31.5 & 44.8 \\
\hline SUNY Stony Brook & 25 & 46.1 & 12.2 & 42.6 & 61.3 \\
\hline Polytechnique (F) & 26 & 56 & 7.6 & 19 & 31.3 \\
\hline UC San Diego & 27 & 69.9 & 5.2 & 19.7 & 33.9 \\
\hline Hebrew U (IL) & 28 & 64.3 & 10.2 & 35.9 & 51 \\
\hline Cambridge (UK) & 29 & 79.8 & 6.2 & 20.7 & 31.8 \\
\hline Illinois at Urbana & 30 & 99.2 & 4.4 & 17.4 & 28.3 \\
\hline
\end{tabular}

Table 18: Size and share of top authors in top departments 


\begin{tabular}{|c|c|c|c|c|}
\hline VARIABLES & $\begin{array}{c}(1) \\
\text { Author Impact (IF) }\end{array}$ & $\begin{array}{c}\text { (2) } \\
\text { Author Impact (IF) }\end{array}$ & $\begin{array}{c}\text { (3) } \\
\text { Author Impact (IF) }\end{array}$ & $\begin{array}{c}\text { (4) } \\
\text { Author Impact (IF) }\end{array}$ \\
\hline Princeton & $\begin{array}{c}13.67^{* * *} \\
(0.670)\end{array}$ & $\begin{array}{c}7.531 \\
(7.304)\end{array}$ & $\begin{array}{c}3.684 \\
(13.62)\end{array}$ & $\begin{array}{c}20.07 \\
(13.56)\end{array}$ \\
\hline U Paris 11 & $\begin{array}{c}5.701^{* * *} \\
(0.650)\end{array}$ & $\begin{array}{l}13.92^{*} \\
(7.871)\end{array}$ & $\begin{array}{l}4.931 \\
(15.58)\end{array}$ & $\begin{array}{l}26.36^{*} \\
(13.72)\end{array}$ \\
\hline MIT & $\begin{array}{c}6.617^{* * * *} \\
(0.576)\end{array}$ & $\begin{array}{l}4.792 \\
(7.350)\end{array}$ & $\begin{array}{c}2.249 \\
(13.63)\end{array}$ & $\begin{array}{l}11.01 \\
(13.49)\end{array}$ \\
\hline NYU & $\begin{array}{c}15.84^{* * *} \\
(0.660)\end{array}$ & $\begin{array}{c}18.93^{* * *} \\
(7.289)\end{array}$ & $\begin{array}{c}19.61 \\
(13.51)\end{array}$ & $\begin{array}{l}23.61^{*} \\
(13.64)\end{array}$ \\
\hline UC Berkeley & $\begin{array}{c}5.397^{* * *} \\
(0.550)\end{array}$ & $\begin{array}{l}3.025 \\
(7.395)\end{array}$ & $\begin{array}{l}-3.340 \\
(13.73)\end{array}$ & $\begin{array}{c}12.28 \\
(13.67)\end{array}$ \\
\hline U Paris 6 & $\begin{array}{c}3.412 * * * \\
(0.581)\end{array}$ & $\begin{array}{l}7.427 \\
(7.975)\end{array}$ & $\begin{array}{l}-16.64 \\
(15.79)\end{array}$ & $\begin{array}{l}26.11^{*} \\
(13.82)\end{array}$ \\
\hline U Chicago & $\begin{array}{c}5.509 * * * \\
(0.722)\end{array}$ & $\begin{array}{l}12.08 \\
(7.604)\end{array}$ & $\begin{array}{l}10.62 \\
(14.36)\end{array}$ & $\begin{array}{l}19.11 \\
(13.75)\end{array}$ \\
\hline UCLA & $\begin{array}{c}2.864 * * * \\
(0.698)\end{array}$ & $\begin{array}{l}9.197 \\
(7.539)\end{array}$ & $\begin{array}{c}9.018 \\
(13.70)\end{array}$ & $\begin{array}{l}23.63^{*} \\
(13.98)\end{array}$ \\
\hline Stanford & $\begin{array}{c}6.347 * * * \\
(0.632)\end{array}$ & $\begin{array}{l}4.958 \\
(7.469)\end{array}$ & $\begin{array}{l}7.026 \\
(14.28)\end{array}$ & $\begin{array}{c}9.300 \\
(13.76)\end{array}$ \\
\hline U Michigan & $\begin{array}{l}-0.628 \\
(0.629)\end{array}$ & $\begin{array}{c}0.414 \\
(7.541)\end{array}$ & $\begin{array}{l}-13.17 \\
(14.24)\end{array}$ & $\begin{array}{c}10.21 \\
(13.82)\end{array}$ \\
\hline Rutgers & $\begin{array}{r}-0.0867 \\
(0.669)\end{array}$ & $\begin{array}{c}7.690 \\
(7.661)\end{array}$ & $\begin{array}{c}13.03 \\
(13.86)\end{array}$ & $\begin{array}{l}17.53 \\
(14.58)\end{array}$ \\
\hline U Maryland & $\begin{array}{c}-0.0430 \\
(0.703)\end{array}$ & $\begin{array}{l}1.027 \\
(7.858)\end{array}$ & $\begin{array}{l}9.034 \\
(14.34)\end{array}$ & $\begin{array}{c}1.723 \\
(15.27)\end{array}$ \\
\hline IAS Princeton & $\begin{array}{l}-4.898^{* * *} \\
(1.099)\end{array}$ & $\begin{array}{c}9.959 \\
(7.602)\end{array}$ & $\begin{array}{l}13.38 \\
(14.17)\end{array}$ & $\begin{array}{l}14.91 \\
(13.77)\end{array}$ \\
\hline Cornell & $\begin{array}{c}0.633 \\
(0.652)\end{array}$ & $\begin{array}{c}3.751 \\
(7.647)\end{array}$ & $\begin{array}{c}6.776 \\
(13.94)\end{array}$ & $\begin{array}{c}10.52 \\
(14.23)\end{array}$ \\
\hline Oxford & $\begin{array}{c}-3.465^{* * *} \\
(0.731)\end{array}$ & $\begin{array}{c}2.533 \\
(8.310)\end{array}$ & $\begin{array}{c}8.221 \\
(16.62)\end{array}$ & $\begin{array}{c}10.56 \\
(14.55)\end{array}$ \\
\hline SUNY Stony Brook & $\begin{array}{c}-6.415^{* * *} \\
(0.998)\end{array}$ & $\begin{array}{c}9.447 \\
(8.510)\end{array}$ & $\begin{array}{c}12.18 \\
(14.84)\end{array}$ & $\begin{array}{c}11.78 \\
(17.14)\end{array}$ \\
\hline Ecole Polytechnique & $\begin{array}{c}-4.857^{* * * *} \\
(0.884)\end{array}$ & $\begin{array}{c}7.034 \\
(8.061)\end{array}$ & $\begin{array}{l}-3.952 \\
(16.21)\end{array}$ & $\begin{array}{c}16.54 \\
(14.12)\end{array}$ \\
\hline Hebrew U & $\begin{array}{c}-5.928 * * * \\
(0.873)\end{array}$ & $\begin{array}{c}2.925 \\
(8.092)\end{array}$ & $\begin{array}{c}7.736 \\
(14.97)\end{array}$ & $\begin{array}{l}-9.118 \\
(14.61)\end{array}$ \\
\hline Cambridge & $\begin{array}{c}-2.631^{* * *} \\
(0.726)\end{array}$ & $\begin{array}{c}8.007 \\
(8.262)\end{array}$ & $\begin{array}{c}19.05 \\
(16.39)\end{array}$ & $\begin{array}{l}15.30 \\
(14.45)\end{array}$ \\
\hline U Illinois & $\begin{array}{c}-4.731^{* * *} \\
(0.668)\end{array}$ & $\begin{array}{c}6.318 \\
(8.179)\end{array}$ & $\begin{array}{c}8.410 \\
(15.92)\end{array}$ & $\begin{array}{c}9.860 \\
(14.33)\end{array}$ \\
\hline U Toulouse 3 & $\begin{array}{c}-8.895^{* * *} \\
(0.900)\end{array}$ & $\begin{array}{c}9.199 \\
(9.021)\end{array}$ & $\begin{array}{c}19.88 \\
(19.91)\end{array}$ & $\begin{array}{c}20.90 \\
(14.83)\end{array}$ \\
\hline ENS Paris & $\begin{array}{c}-6.966 * * * \\
(1.011)\end{array}$ & $\begin{array}{l}8.520 \\
(8.106)\end{array}$ & $\begin{array}{l}-13.18 \\
(16.60)\end{array}$ & $\begin{array}{c}21.69 \\
(13.74)\end{array}$ \\
\hline ETH Zürich & $\begin{array}{c}-4.842^{* * *} \\
(0.864)\end{array}$ & $\begin{array}{l}1.472 \\
(6.808)\end{array}$ & $\begin{array}{l}12.70 \\
(10.99)\end{array}$ & $\begin{array}{c}8.289 \\
(13.62)\end{array}$ \\
\hline Tel Aviv U & $\begin{array}{c}-4.911 * * * \\
(0.732)\end{array}$ & $\begin{array}{l}4.277 \\
(7.952)\end{array}$ & $\begin{array}{c}8.840 \\
(15.18)\end{array}$ & $\begin{array}{c}9.269 \\
(14.16)\end{array}$ \\
\hline U Bonn & $\begin{array}{c}-6.695^{* * *} \\
(0.884)\end{array}$ & $\begin{array}{c}0 \\
(0)\end{array}$ & $\begin{array}{c}0 \\
(0)\end{array}$ & $\begin{array}{c}0 \\
(0)\end{array}$ \\
\hline Constant & $\begin{array}{c}13.34^{* * *} \\
(0.797)\end{array}$ & $\begin{array}{c}25.31^{* * *} \\
(8.240)\end{array}$ & $\begin{array}{l}25.22^{*} \\
(14.78)\end{array}$ & $\begin{array}{c}15.01 \\
(14.54)\end{array}$ \\
\hline $\begin{array}{l}\text { Author Fixed Effects } \\
\text { R-squared } \\
\text { Observations } \\
\text { Number of Authors } \\
\text { Period }\end{array}$ & $\begin{array}{c}\text { No } \\
208683\end{array}$ & $\begin{array}{l}\text { Yes } \\
0.040 \\
21597 \\
8159\end{array}$ & $\begin{array}{c}\text { Yes } \\
0.046 \\
8913 \\
4064 \\
<1995 \\
\end{array}$ & $\begin{array}{c}\text { Yes } \\
0.045 \\
12684 \\
5613 \\
>1994 \\
\end{array}$ \\
\hline
\end{tabular}

Table 19: Fixed effects of major departments, by IF 


\begin{tabular}{|c|c|c|c|c|c|}
\hline VARIABLES & $\begin{array}{c}\text { (1) } \\
\text { Author } \\
\text { Impact (IF) }\end{array}$ & $\begin{array}{c}(2) \\
\text { Author } \\
\text { Impact (IF) }\end{array}$ & $\begin{array}{c}(3) \\
\text { Author } \\
\text { Impact (IF) }\end{array}$ & $\begin{array}{c}(4) \\
\text { Author } \\
\text { Impact (IF) }\end{array}$ & $\begin{array}{c}(5) \\
\text { Author } \\
\text { Impact (IF) }\end{array}$ \\
\hline Princeton & $\begin{array}{c}7.531 \\
(7.304)\end{array}$ & $\begin{array}{c}1.605 \\
(6.864)\end{array}$ & $\begin{array}{c}5.832 \\
(6.665)\end{array}$ & $\begin{array}{c}9.125 \\
(7.306)\end{array}$ & $\begin{array}{c}8.075 \\
(7.315)\end{array}$ \\
\hline U Paris 11 & $\begin{array}{l}13.92^{*} \\
(7.871)\end{array}$ & $\begin{array}{c}11.90 \\
(7.397)\end{array}$ & $\begin{array}{c}15.13^{* *} \\
(7.182)\end{array}$ & $\begin{array}{c}12.76 \\
(7.874)\end{array}$ & $\begin{array}{l}14.07^{*} \\
(7.883)\end{array}$ \\
\hline NYU & $\begin{array}{c}18.93^{* * *} \\
(7.289)\end{array}$ & $\begin{array}{l}-1.008 \\
(6.850)\end{array}$ & $\begin{array}{c}21.42^{* * *} \\
(6.651)\end{array}$ & $\begin{array}{c}20.05^{* * *} \\
(7.291)\end{array}$ & $\begin{array}{c}19.33^{* * *} \\
(7.300)\end{array}$ \\
\hline IAS Princeton & $\begin{array}{c}9.959 \\
(7.602)\end{array}$ & $\begin{array}{c}4.070 \\
(7.143)\end{array}$ & $\begin{array}{l}11.61^{*} \\
(6.936)\end{array}$ & $\begin{array}{l}10.28 \\
(7.604)\end{array}$ & $\begin{array}{c}10.73 \\
(7.613)\end{array}$ \\
\hline Ecole Polytechnique & $\begin{array}{c}7.034 \\
(8.061)\end{array}$ & $\begin{array}{c}3.685 \\
(7.575)\end{array}$ & $\begin{array}{c}8.475 \\
(7.355)\end{array}$ & $\begin{array}{c}6.849 \\
(8.063)\end{array}$ & $\begin{array}{c}6.047 \\
(8.072)\end{array}$ \\
\hline ENS Paris & $\begin{array}{c}8.520 \\
(8.106)\end{array}$ & $\begin{array}{c}9.214 \\
(7.617)\end{array}$ & $\begin{array}{c}9.873 \\
(7.396)\end{array}$ & $\begin{array}{c}8.782 \\
(8.108)\end{array}$ & $\begin{array}{c}9.009 \\
(8.117)\end{array}$ \\
\hline Constant & $\begin{array}{c}25.31^{* * *} \\
(8.240)\end{array}$ & $\begin{array}{c}25.03^{* * *} \\
(7.743)\end{array}$ & $\begin{array}{c}22.06^{* * *} \\
(7.519)\end{array}$ & $\begin{array}{c}24.63^{* * *} \\
(8.243)\end{array}$ & $\begin{array}{c}24.21^{* * *} \\
(8.252)\end{array}$ \\
\hline R-squared & 0.040 & 0.040 & 0.043 & 0.039 & 0.039 \\
\hline Observations & 21597 & 21597 & 21597 & 21597 & 21597 \\
\hline Number of Authors & 8159 & 8159 & 8159 & 8159 & 8159 \\
\hline Removed & None & CPAM & Annals & IHES & E.N.S. \\
\hline
\end{tabular}

Table 20: Fixed effects of a selection of major departments, with some journals removed, by IF 


\begin{tabular}{lcccc}
\hline \multirow{2}{*}{ Dep. Variable } & $(1)$ & $(2)$ & $(3)$ & $(4)$ \\
& Author Impact & Author Impact & Nb. Articles & Nb. Articles \\
coaut & & & & \\
& $-6.462^{* * *}$ & $-5.945^{* * *}$ & $0.0314^{* * *}$ & $0.0294^{* * *}$ \\
Age & $(0.0906)$ & $(0.0842)$ & $(0.00275)$ & $(0.00255)$ \\
& $0.762^{* * *}$ & $0.493^{* * *}$ & $0.0306^{* * *}$ & $0.0228^{* * *}$ \\
Age $^{2}$ & $(0.0408)$ & $(0.0508)$ & $(0.00156)$ & $(0.00163)$ \\
& $-0.0330^{* * *}$ & $-0.0201^{* * *}$ & $-0.00123^{* * *}$ & $-0.000868^{* * *}$ \\
Age $^{3}$ & $(0.00207)$ & $(0.00240)$ & $(9.08 \mathrm{e}-05)$ & $(8.27 \mathrm{e}-05)$ \\
& $0.000356^{* * *}$ & $0.000175^{* * *}$ & $1.32 \mathrm{e}-05^{* * *}$ & $8.37 \mathrm{e}-06^{* * *}$ \\
Univ. Specialization Index_univ $^{*}$ & $(2.90 \mathrm{e}-05)$ & $(3.55 \mathrm{e}-05)$ & $(1.41 \mathrm{e}-06)$ & $(1.26 \mathrm{e}-06)$ \\
Size University & $-4.301^{* * *}$ & $3.607^{* * *}$ & $-0.0419^{*}$ & $0.110^{* * *}$ \\
& $(0.585)$ & $(0.741)$ & $(0.0227)$ & $(0.0273)$ \\
Stability & $0.106^{* * *}$ & $0.0416^{* * *}$ & $0.00260^{* * *}$ & $0.00201^{* * *}$ \\
& $(0.00378)$ & $(0.00410)$ & $(0.000139)$ & $(0.000133)$ \\
Constant & $-7.395^{* * *}$ & 1.232 & 0.0148 & 0.0244 \\
& $(0.860)$ & $(1.234)$ & $(0.0349)$ & $(0.0422)$ \\
& $18.84^{* * *}$ & $24.76^{* * *}$ & $0.950^{* * *}$ & $1.200^{* * *}$ \\
Author Fixed Effects & $(1.098)$ & $(1.232)$ & $(0.0340)$ & $(0.0445)$ \\
Year Fixed Effects & & & & \\
Field Fixed Effects & No & Yes & No & Yes \\
R-squared & Yes & Yes & Yes & Yes \\
Observations & Yes & Yes & Yes & Yes \\
Number of Authors & 0.093 & 0.041 & 0.028 & 0.008 \\
\hline & 138707 & 138707 & 138707 & 138707 \\
& & 30266 & & 30266 \\
\hline
\end{tabular}

Table 21: Impact, effect of various variables, based on IF 


\begin{tabular}{|c|c|c|}
\hline VARIABLES & $\begin{array}{c}\text { (1) } \\
\text { Author Impact }\end{array}$ & $\begin{array}{c}(2) \\
\text { Author Impact }\end{array}$ \\
\hline Nb. of coauthors & $\begin{array}{c}-8.131^{* * *} \\
(0.221)\end{array}$ & $\begin{array}{c}-7.432^{* * *} \\
(0.218)\end{array}$ \\
\hline Age & $\begin{array}{c}1.359^{* * *} \\
(0.0926)\end{array}$ & $\begin{array}{c}0.642^{* * *} \\
(0.124)\end{array}$ \\
\hline $\mathrm{Age}^{2}$ & $\begin{array}{c}-0.0540^{* * *} \\
(0.00444)\end{array}$ & $\begin{array}{c}-0.0250^{* * *} \\
(0.00567)\end{array}$ \\
\hline $\mathrm{Age}^{3}$ & $\begin{array}{c}0.000546^{* * *} \\
(5.83 \mathrm{e}-05)\end{array}$ & $\begin{array}{c}0.000179^{* *} \\
(7.80 \mathrm{e}-05)\end{array}$ \\
\hline Univ. Specialization Index & $\begin{array}{l}4.850 \\
(5.942)\end{array}$ & $\begin{array}{l}5.805 \\
(6.119)\end{array}$ \\
\hline Size of University & $\begin{array}{c}0.0738^{* * *} \\
(0.00663)\end{array}$ & $\begin{array}{c}0.0621^{* * *} \\
(0.0102)\end{array}$ \\
\hline Closeness & $\begin{array}{c}-27.76^{* * *} \\
(5.010)\end{array}$ & $\begin{array}{l}-3.871 \\
(7.232)\end{array}$ \\
\hline Private University & $\begin{array}{c}3.176^{* * * *} \\
(0.511)\end{array}$ & $\begin{array}{c}1.824^{* *} \\
(0.838)\end{array}$ \\
\hline Endowment per Student & $\begin{array}{c}3.207^{* * *} \\
(0.883)\end{array}$ & $\begin{array}{l}-1.419 \\
(1.043)\end{array}$ \\
\hline East Coast University & $\begin{array}{c}2.301^{* * *} \\
(0.469)\end{array}$ & $\begin{array}{c}2.261^{* * *} \\
(0.869)\end{array}$ \\
\hline West Coast University & $\begin{array}{c}1.711^{* * *} \\
(0.608)\end{array}$ & $\begin{array}{l}0.839 \\
(1.053)\end{array}$ \\
\hline Constant & $\begin{array}{c}35.78^{* * *} \\
(5.975)\end{array}$ & $\begin{array}{c}32.59^{* * *} \\
(6.637)\end{array}$ \\
\hline Author Fixed Effects & No & Yes \\
\hline Year Fixed Effects & Yes & Yes \\
\hline Field Fixed Effects & Yes & Yes \\
\hline R-squared & 0.092 & 0.041 \\
\hline Observations & 37320 & 37320 \\
\hline Number of Authors & & 9121 \\
\hline
\end{tabular}

Table 22: The determinants of mathematicians' scientific output, without/with fixed effects, US only 


\begin{tabular}{lccc}
\hline & $(1)$ & $(2)$ & $(3)$ \\
Dep. Variable & & & \\
& Author Impact & Author Impact & Author Impact \\
Nb. of coauthors & $-4.737^{* * *}$ & $-5.125^{* * *}$ & $-4.749^{* * *}$ \\
& $(0.0759)$ & $(0.104)$ & $(0.0758)$ \\
Nb. coauthors diff specialty & $2.161^{* * *}$ & $3.506^{* * *}$ & $2.120^{* * *}$ \\
& $(0.220)$ & $(0.239)$ & $(0.220)$ \\
Nb. past moves & $1.290^{* * *}$ & $0.878^{* * *}$ & $1.461^{* * *}$ \\
& $(0.126)$ & $(0.165)$ & $(0.126)$ \\
pdisc & $0.754^{* * *}$ & 0.0884 & $0.815^{* * *}$ \\
& $(0.183)$ & $(0.278)$ & $(0.183)$ \\
Nb. of past MSC codes & $0.695^{* * *}$ & $0.783^{* * *}$ & $0.777^{* * *}$ \\
& $(0.157)$ & $(0.232)$ & $(0.157)$ \\
Nb. of past coauthors & $0.997^{* * *}$ & $0.483^{* * *}$ & $1.019^{* * *}$ \\
& $(0.0815)$ & $(0.0792)$ & $(0.0812)$ \\
Constant & $14.10^{* * *}$ & $17.38^{* * *}$ & $17.81^{* * *}$ \\
& $(0.592)$ & $(1.194)$ & $(0.740)$ \\
& & & \\
Author Fixed Effect & No & Yes & No \\
Year Fixed Effects & Yes & Yes & Yes \\
Field Fixed Effects & Yes & Yes & Yes \\
3 Year Cohort Effects & No & No & Yes \\
R-squared & 0.134 & 0.049 & 0.137 \\
Observations & 108447 & 108447 & 108447 \\
Number of Authors & & 44875 & \\
\hline
\end{tabular}

Table 23: Effect of individual variables on mathematician's output, by IF 


\begin{tabular}{|c|c|c|c|c|c|c|c|}
\hline \multirow[t]{2}{*}{ journal } & \multicolumn{7}{|c|}{ Mean } \\
\hline & Total Pages & $\mathrm{Nb}$. & Articles & M.C.Q. & Pages & $\mathrm{Nb}$. & Authors \\
\hline $\mathrm{ACHA}$ & 15953 & & 819 & 0.83 & 19.48 & & 2.50 \\
\hline ACMMS & 12581 & & 756 & 0.49 & 16.64 & & 2.5 \\
\hline Acta & 23678 & & 585 & 2.14 & 40.48 & & 2.09 \\
\hline AdvApplProba & 43739 & & 2360 & 0.36 & 18.53 & & 2.07 \\
\hline AdvCompMath & 20798 & & 961 & 0.63 & 21.64 & & 2.35 \\
\hline Advances & 94806 & & 2711 & 1.04 & 34.97 & & 2.06 \\
\hline AJM & 48824 & & 1691 & 1.03 & 28.87 & & 1.89 \\
\hline AnnApplProba & 45783 & & 1790 & 0.81 & 25.58 & & 2.22 \\
\hline AnnProba & 79936 & & 3396 & 0.89 & 23.54 & & 1.99 \\
\hline AnnStat & 87197 & & 4140 & 0.75 & 21.06 & & 2.03 \\
\hline Annals & 63255 & & 1605 & 1.98 & 39.41 & & 1.98 \\
\hline Arkiv & 12884 & & 710 & 0.64 & 18.15 & & 1.79 \\
\hline ASENS & 27757 & & 846 & 1.19 & 32.81 & & 1.78 \\
\hline BAMS & 13372 & & 1044 & 2.03 & 12.81 & & 1.97 \\
\hline Bernoulli & 19542 & & 915 & 0.40 & 21.36 & & 2.23 \\
\hline Biometrika & 36867 & & 3622 & 0.38 & 10.18 & & 2.16 \\
\hline $\mathrm{CMH}$ & 26054 & & 1285 & 0.92 & 20.28 & & 1.90 \\
\hline CombProbaComput & 16808 & & 1127 & 0.34 & 14.91 & & 2.31 \\
\hline Combinatorica & 23545 & & 1654 & 0.44 & 14.24 & & 2.31 \\
\hline CommPDE & 69948 & & 2495 & 0.94 & 28.04 & & 1.90 \\
\hline Compositio & 52333 & & 2233 & 0.76 & 23.44 & & 1.76 \\
\hline ComputComp & 10917 & & 470 & 0.33 & 23.23 & & 2.84 \\
\hline Constr & 22313 & & 1115 & 0.71 & 20.01 & & 2.12 \\
\hline CPAM & 59562 & & 1844 & 1.67 & 32.30 & & 2.18 \\
\hline Crelle & 89626 & & 3568 & 0.91 & 25.12 & & 1.85 \\
\hline DCDS & 34491 & & 2249 & 0.40 & 15.34 & & 2.21 \\
\hline DCG & 38155 & & 2291 & 0.50 & 16.65 & & 2.44 \\
\hline Duke & 91063 & & 3093 & 1.38 & 29.44 & & 1.93 \\
\hline DynSys & 4707 & & 232 & 0.33 & 20.29 & & 2.31 \\
\hline Econometrica & 42090 & & 1832 & 0.70 & 22.97 & & 2.04 \\
\hline ElecJComb & 22490 & & 1613 & 0.44 & 13.94 & & 2.20 \\
\hline ElectrCommunProba & 3201 & & 331 & 0.63 & 9.67 & & 2.03 \\
\hline ElectronJProba & 14833 & & 500 & 0.55 & 29.67 & & 2.25 \\
\hline Expo & 12656 & & 674 & 0.44 & 18.78 & & 1.68 \\
\hline FinancStoch & 8686 & & 419 & 0.78 & 20.73 & & 2.29 \\
\hline GAFA & 29987 & & 960 & 1.17 & 31.24 & & 1.97 \\
\hline GeoTopo & 16950 & & 461 & 1.28 & 36.77 & & 1.95 \\
\hline IHES & 16881 & & 330 & 2.71 & 51.15 & & 2.02 \\
\hline IhpProba & 26998 & & 1145 & 0.69 & 23.58 & & 2.01 \\
\hline IhpAN & 29750 & & 1130 & 1.26 & 26.33 & & 2.10 \\
\hline IMAJNA & 27521 & & 1401 & 0.63 & 19.64 & & 2.17 \\
\hline Indiana & 54789 & & 2254 & 0.91 & 24.31 & & 2.02 \\
\hline InfinDimAnal & 10403 & & 561 & 0.62 & 18.54 & & 2.15 \\
\hline Inventiones & 93613 & & 3220 & 1.94 & 29.07 & & 1.87 \\
\hline Inverse & 54049 & & 3569 & 0.81 & 15.14 & & 2.42 \\
\hline Irmn & 41359 & & 1978 & 0.95 & 20.91 & & 1.95 \\
\hline JAmStatAssoc & 44051 & & 4339 & 0.47 & 10.15 & & 2.37 \\
\hline JCombThA & 49950 & & 3414 & 0.54 & 14.63 & & 2.11 \\
\hline JCombThB & 38601 & & 2501 & 0.63 & 15.43 & & 2.26 \\
\hline
\end{tabular}

Table 24: Journals 45 the database, A-J 


\begin{tabular}{|c|c|c|c|c|c|c|c|}
\hline \multirow[t]{2}{*}{ journal } & \multicolumn{7}{|c|}{ Mean } \\
\hline & Total Pages & $\mathrm{Nb}$. & Articles & M.C.Q. & Pages & $\mathrm{Nb}$. & Authors \\
\hline JGeomPhys & 45937 & & 2209 & 0.38 & 20.80 & & 2.19 \\
\hline JRStatSocB & 17309 & & 947 & 0.59 & 18.28 & & 2.52 \\
\hline JStatPlan & 95233 & & 6402 & 0.28 & 14.88 & & 2.18 \\
\hline JTheorProba & 28841 & & 1392 & 0.38 & 20.72 & & 1.95 \\
\hline JAG & 17880 & & 655 & 0.78 & 27.30 & & 1.83 \\
\hline JAMS & 34388 & & 1000 & 2.54 & 34.39 & & 2.11 \\
\hline JCryptol & 10009 & & 475 & 0.36 & 21.07 & & 2.56 \\
\hline JDE & 149292 & & 5822 & 0.91 & 25.64 & & 2.03 \\
\hline JDG & 52365 & & 1632 & 1.19 & 32.09 & & 1.82 \\
\hline JEMS & 6895 & & 230 & 1.42 & 29.98 & & 2.25 \\
\hline JFA & 161178 & & 5732 & 0.97 & 28.12 & & 2.08 \\
\hline JLMS & 50910 & & 3667 & 0.65 & 13.88 & & 1.94 \\
\hline JMAA & 268584 & & 17941 & 0.47 & 14.97 & & 2.05 \\
\hline JMPA & 36215 & & 1255 & 1.03 & 28.86 & & 2.18 \\
\hline JNLS & 18661 & & 637 & 0.75 & 29.30 & & 2.44 \\
\hline MAMS & 107327 & & 984 & 1.58 & 109.07 & & 2.11 \\
\hline MathAnn & 82398 & & 4237 & 0.96 & 19.45 & & 1.81 \\
\hline MathComput & 69607 & & 4263 & 0.68 & 16.33 & & 2.12 \\
\hline MathProg & 72525 & & 3659 & 0.65 & 19.82 & & 2.32 \\
\hline MathZ & 75035 & & 4401 & 0.62 & 17.05 & & 1.80 \\
\hline MRL & 18007 & & 1503 & 0.75 & 11.98 & & 1.98 \\
\hline Nonlinearity & 62933 & & 3168 & 0.55 & 19.87 & & 2.33 \\
\hline NumLinAlgA & 17725 & & 1000 & 0.39 & 17.73 & & 2.49 \\
\hline NumerMath & 77775 & & 3603 & 0.75 & 21.59 & & 2.20 \\
\hline PTRF & 64525 & & 2709 & 0.92 & 23.82 & & 1.94 \\
\hline PhysicaD & 130332 & & 7418 & 0.33 & 17.57 & & 2.64 \\
\hline PLMS & 53111 & & 1892 & 0.99 & 28.07 & & 2.01 \\
\hline PublMath & 15861 & & 906 & 0.41 & 17.51 & & 1.83 \\
\hline QJM & 18410 & & 1319 & 0.54 & 13.96 & & 1.91 \\
\hline Random & 27551 & & 1343 & 0.57 & 20.51 & & 2.38 \\
\hline RMIbero & 23016 & & 771 & 0.71 & 29.85 & & 2.04 \\
\hline ScandJStat & 20070 & & 1327 & 0.29 & 15.12 & & 2.10 \\
\hline SiamCO & 80559 & & 3795 & 0.71 & 21.23 & & 2.14 \\
\hline SiamJAM & 89115 & & 4291 & 0.49 & 20.77 & & 2.41 \\
\hline SiamJC & 80871 & & 4130 & 0.40 & 19.58 & & 2.71 \\
\hline SiamJMAA & 44987 & & 2737 & 0.67 & 16.44 & & 2.33 \\
\hline SiamJSC & 65780 & & 3299 & 0.61 & 19.94 & & 2.57 \\
\hline SiamMA & 69467 & & 3636 & 0.91 & 19.11 & & 2.08 \\
\hline SiamNA & 93630 & & 4513 & 0.79 & 20.75 & & 2.27 \\
\hline SiamOpti & 38298 & & 1897 & 1.08 & 20.19 & & 2.42 \\
\hline SiamRev & 22594 & & 1008 & 1.01 & 22.41 & & 2.18 \\
\hline SochProcAppl & 61820 & & 3320 & 0.57 & 18.62 & & 1.98 \\
\hline StatSci & 11825 & & 605 & 0.23 & 19.55 & & 2.13 \\
\hline StatSinica & 29945 & & 1711 & 0.23 & 17.50 & & 2.33 \\
\hline StudAM & 31616 & & 1287 & 0.31 & 24.57 & & 2.22 \\
\hline TAMS & 187528 & & 8770 & 0.83 & 21.38 & & 1.93 \\
\hline Topology & 34157 & & 1732 & 0.82 & 19.72 & & 1.85 \\
\hline Total & 85963 & & 4584 & 0.74 & 20.83 & & 2.13 \\
\hline
\end{tabular}

Table 25: Journals in the database, J-Z 